\title{
PREDICTION OF MECHANICAL ALTERATIONS IN MULTI-LAYER SBS-MODIFIED HOT MIX ASPHALT AND SOIL-FOUNDATION STRUCTURE
}

\author{
AHMET SERTAC KARAKAS ${ }^{* 1}$, FARUK ORTES ${ }^{2}$ \\ ${ }^{1}$ Construction and Technical Department, Istanbul University, Istanbul, Turkey \\ ${ }^{2}$ Department of Mechanical Engineering, Istanbul University-Cerrahpasa, \\ Istanbul, Turkey
}

Received 22 December 2020; accepted 7 April 2021

\begin{abstract}
Traffic and environmental conditions are key parameters in road applications. Empirical studies and numerical analyses, which are widely adopted in material design studies, are used for analysing superstructures of the roads, and developmental approaches are improved for future designs as well. In flexible pavements, polymer and fibre-reinforced additives are frequently used to make them durable against deteriorations and to extend their service life. One of the additives that is mostly preferred is the Styrene Butadiene Styrene (SBS) material thanks to a variety of their physical and chemical properties. Physical and mechanical properties of the natural ground layer and its interactions with the superstructure are crucial parameters in terms of performance under various environmental and traffic conditions. In this study, the use of SBS-modified Hot Mix Asphalt (HMA) was examined as a flexible superstructure, and the mechanical properties of the granular base and the natural ground layer were tested. The stress and deformation occurring within layers in various periods were also considered. The presented study
\end{abstract}

\footnotetext{
* Corresponding author. E-mail: skarakas@istanbul.edu.tr

Ahmet Sertac KARAKAS (ORCID ID 0000-0002-0840-2878)

Faruk ORTES (ORCID ID 0000-0003-4802-3810) 
is a suitable tool for the use of additives that significantly contribute to the mechanical properties and service life of the roads. In this study, it is concluded that the use of additives significantly improves the mechanical response and service life of the roads.

Keywords: hot mix asphalt, SBS polymer, multi-layer asphalt, soil structure, finite element method, regression analysis.

\section{Introduction}

Transportation via highways is used commonly for freight and passenger transportation, and the rate of using highways for transportation rapidly increases due to the increasing population and growing needs of societies. Flexible pavements prepared with Hot Mix Asphalt (HMA) are one of the most common types of superstructures used in highway transportation. In face of their intensive use, highways are expected to serve for long periods and demonstrate the expected performance throughout their service life. Since the raw materials used in the superstructures of the roads are limited, it is necessary to use the available materials by considering methods to improve them such as recycling or including additives. Various types of additives are used to preserve the endurance of highway pavements throughout their service life under environmental and traffic conditions. Materials including polymers and fibres are among the most common additives used in this manner. As SBS polymers significantly contribute to the endurance of HMA, they are among the most common additives investigated and examined in recent years. In order to improve the binding properties of asphalts, which cover adhesion, cohesion, durability, and to extend their service life, various modifiers, such as lime, acid, polymer, carbon fibre, and anti-stripping chemicals, are used in binder modifications (Tarefder \& Zaman, 2016).

In recent years, two types of significant modifiers have been used in asphalt modifications. Fibres and polymers, such as Butadiene Rubber (SBR), Butadiene Styrene (SBS), Styrene, Ethyl Vinyl Acetate (EVA), Carbon Fibre, and Crumb Rubber, are among the modifiers that are used for this purpose. SBS modifiers increase the unsatisfactory temperature performance of modified asphalt binders while improving their strength against permanent deformation and high-temperature performance (Yao \& You, 2016).

Polymer modification is commonly used in asphalt binders to increase the Wheel Track Resistance and Crack Resistance performance of asphalt mixtures (Ullidtz, 1987). Although asphalt is a composite material, modelling studies on asphalt are performed by using it as an equivalent of isotropic and homogeneous material. Additionally, 
asphalt pavements act as linearly elastic and fragile material in subzero temperatures (Novak et al., 2003; Akbulut \& Aslantas, 2005; Kim \& Wagoner, 2009; Li \& Marasteanu, 2010). Recently, recycled materials have also been one of the most prominent alternatives used in pavement modification. In modified asphalt mixtures, a variety of additives based on recycled materials, such as crumb rubber, waste polyethylene plastic, steel slags, were also examined through experimental works (Xiao, et al., 2009; Wu et al., 2007; Hinislioglu \& Agar, 2004). Yang et al. (2015) examined the performance of asphalt pavements under heavy traffic loads and conducted empirical studies by designing SBS-modified asphalt mixtures at six different gradation levels. In the study, the authors observed that the porosity of the asphalt mixtures affected the performance of asphalt pavements significantly (Yang et al., 2015). Li et al. (2016) tested the high-temperature properties and viscosities of asphalt materials for the four different layers with a Pivoted Rheometer device. The results revealed that rubber and SBS-modified asphalts generally demonstrated satisfactory results in terms of pavement performance in intermediate layers (Sheng et al., 2016). Sengoz and Isikyar (2008) evaluated modified bitumen that contained Ethylene Vinyl Acetate (EVA) copolymers and SBS. In the study, it was found that the morphology and properties of the modified bitumen and the mechanical properties of polymer-modified HMA highly depended on the type and content of the selected polymer. It was also reported that polymer modification enhanced the penetration, softening point, and temperature sensitivity of traditional bitumen. Furthermore, it was specified that the HMA Marshall Stability values, which were prepared with polymer modified bitumen (PMB), were increased as the polymer content increased (Sengoz \& Isikyar 2008). Chen and Huang (2007) examined the mechanical properties of asphalts modified with SBS and sulfur. In the study, viscosity, microscopy, and rheological tests were conducted to investigate the engineering characteristics of polymermodified asphalts (Chen \& Huang, 2007). Prowell et al. (2007) examined asphalt production under accelerated loading tests and determined that warm-mix asphalt and hot-mix asphalt demonstrated similar performance in terms of rutting sensitivity in laboratory tests.

Significant studies have recently investigated permanent deformation and fatigue cracks due to rutting, which is the most common deformation in asphalt pavements. The characteristics of materials, environmental conditions, and pavement structures play significant roles in such deformations. Norouzi et al. (2016) investigated the pavement design properties of superstructures on a $7.7 \mathrm{~km}$-long road. In the study, it was determined that the thicknesses of the pavement and the types of base layers affected the fatigue cracks and
Prediction of Mechanical Alterations in MultıLayer SBS-Modified Hot Mix Asphalt and Soil-Foundation Structure 
rutting performance. However, the sub-base layer thickness and antifrost layers did not exhibit significant effects on deformations.

Deng et al. (2004) investigated the influences of deformations in asphalt pavements in non-homogeneous roadbed areas. Different stressstrain properties were observed in the pavement layers. Li et al. (2016) conducted repetitive continuous deformation tests by using an X-Ray Computer Tomography device to determine asphalt mixture properties and the micro-characteristic structures of pavements. In the study, the deformations observed in various types and layers of pavements were also examined. Siddharthan et al. (1998) investigated the stress behaviours of pavements under real traffic loads by formulating them with the Continuous Base Finite Layer Approach. In the study, the researchers observed that the shear stress was not influential on the contact surface of rubber-asphalt pavements in terms of the tensile stress of the asphalt concrete pavement. Ameri et al. (2011) examined the top-down crack transfer of asphalt pavements under traffic loads by using the 3D finite element approach. The stresses and stress intensity factors were computed for various distance values between the cracks and the wheels of the vehicles. The crack parameters and the T-stress values were computed to analyse the crack resistance and the remaining service life of the asphalt pavements, which were cracked under traffic loads. In the study, these parameters depended mostly on the position of the vehicle wheels with respect to the crack plane (Ameri et al., 2011). Zafir et al. (1994) investigated the Dynamic Pavement-Shape Shifting Behaviour under moving vehicle load. In the study, the researchers observed that there was a strong functionality between the thickness of the pavement, vehicle speed, and their influences on the deformation in the pavements. Zeng and Huang (2004) investigated the behaviours of asphalt pavements under extreme loads and reported that the surface shear stress, base, and sub-base stress, and sub-base pressure stresses increased as the axial loads increased. Recently, studies focusing on the mechanical response of the superstructure of the asphalt layers involving pavement, base, and sub-base components under the traffic and environmental conditions have been carried out using SBS modified and unmodified HMA (Karakas \& Ortes, 2017).

It seems that a huge amount of literature focuses on the sub-base, base, and pavement layers in the design of road superstructures through experimental and numerical investigations. In the literature review, it was also observed that the studies were generally conducted on sub-base, base, and pavement layers while designing superstructures of roads in laboratories and under suitable conditions. However, the destinations, on which the road design studies are planned to be conducted, should be evaluated in terms of the properties of the 
natural ground layers, which consist of various layers, in addition to the superstructure of roads to obtain results presenting an extensive insight. The stress-deformation status of natural ground layers and the superstructure of roads under different loads influence the performance of these layers throughout their service life in addition to playing a role in deformations. Furthermore, although numerous studies were conducted on stress and deformations under different loads and environmental conditions on the natural ground layer, a limited number of studies were conducted on the interaction between the superstructure and natural ground layers.

In this study, the performance of SBS-modified HMA as a flexible superstructure was evaluated by considering and testing the mechanical properties of the granular base and the natural ground layer. The whole structure of the roads, including several layers, was examined under various traffic and environmental conditions within one year. For this purpose, empirical and numerical analyses were conducted comparatively. In the study, the effects of stress and deformations, which were obtained from quantitative analyses and which were caused by structure and base interactions at various layers, were evaluated as well.

\section{Materials and methods}

\subsection{Field works and experimental procedures}

Within the framework of the study, empirical and numerical analyses were conducted. The empirical analyses included steps of field and laboratory tests. The laboratory phase of the study covered bitumen, aggregate, and mixture tests while the field phase covered steps such as evaluation of traffic conditions on the roads, which were designed as pure and SBS-modified HMA, drilling studies to determine ground layers, and obtaining core samples for empirical evaluations. In the numerical analyses, commercial finite element software was employed. Accordingly, the changes in stress and deformation in the superstructure and sub-layers were examined by considering the element of time.

First, the materials to be used in the road platform, which would be prepared with HMA, were chosen. The calcareous-type broken stone aggregate materials were used as the aggregate. The aggregates used in the hot mixture were obtained by breaking the Cebecikoy limestone, which was obtained from the Cebeci Quarry, in a stone crusher machine. The types and contents of the materials, which included the asphalt concrete pavement prepared with HMA, were determined and evaluated in terms of endurance and service life. Specifically, B50/70 class bitumen
Prediction of Mechanical Alteratıons in MultıLayer SBS-Modified Hot Mix Asphalt and Soil-Foundation Structure 
was used as the pure binder. Moreover, SBS block copolymer was chosen as the modifier additive. Numerous advantages were observed when the structure of the SBS was evaluated in previous studies. Since the polymer material is a thermoplastic elastomer, it preserves its characteristics from $-40{ }^{\circ} \mathrm{C}$ to $80^{\circ} \mathrm{C}$ and does not lose its characteristics while heating or cooling (Ahmedzade et al., 2007).

The study was conducted on a secondary road in the Kucukcekmece region of the city of Istanbul in Turkey. The HMA was provided from the plants located in the Sultanciftligi area of Istanbul and bitumen was obtained from the TUPRAS refinery.

In order to implement the field works and laboratory tests, asphalt pavement layers were applied in the previously mentioned region (Kucukcekmece - Istanbul). Following a pre-defined time period required for a vehicle pass, several specimens were obtained from this road structure using a drill machine (Fig. 1).

In the field study, the QTT (NC 200) device was used to determine the types and numbers of vehicles in the area of the study. The QTT (NC 200) Traffic Analysis devices are vehicle detectors that do not require additional sensors. The devices are placed in the centre of the road under a protective cover, and the vehicles pass over them. They also do not require physical contact to identify vehicle activities. The QTT Traffic Analysis device works on the principle that vehicles move towards the

a)

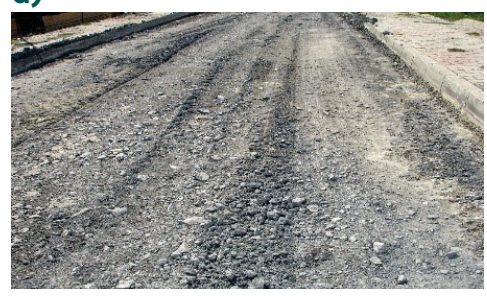

d)

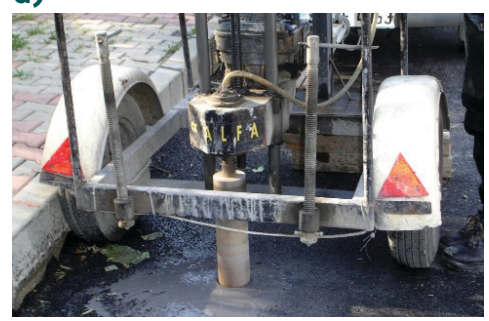

b)

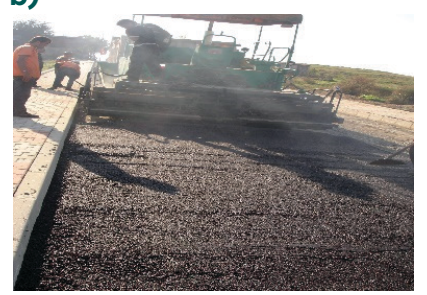

e)

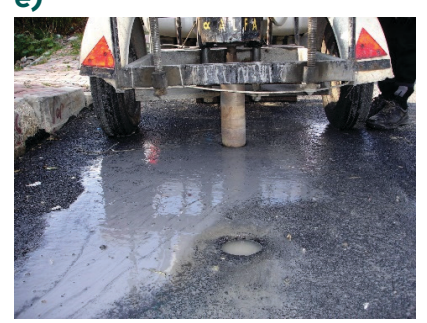

c)

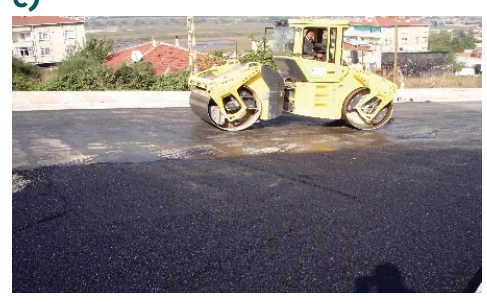

f)

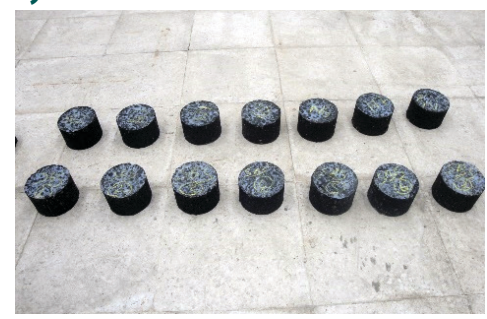

Figure 1. Field work tasks to obtain samples: a) laying out of base layer, b) asphalt pavement layer, c) compression of the asphalt pavement layer, d) core sample machine, e) taking core samples, and f) Marshall test samples 
magnetic field of the earth, and uses the VMI (Vehicle Magnetic Imaging) to detect the vehicles. In detail, the principle on which the device function could be explained in the following way. If a vehicle passes over the Traffic Analysis device, the iron particles in its structure interact with the magnetic field of the earth. Then, this interaction causes changes in electrical signals within the sensors of the device. As a result, the QTT Traffic Analysis device determines the presences of vehicles, counts them, measures their speeds, and records their lengths. The device also reports the surface temperature of the road. The imaging and detection of vehicles by the sensors are demonstrated in Fig. 2.

The core samples were obtained by drilling to determine the properties of the superstructure and the types and depths of the layers. The samples that were obtained by drilling were taken from both pure and SBS-modified asphalt concrete pavements. Accordingly, the samples were labelled in four different ways by considering their locations, such as wheel pass and roadside areas. The abbreviations and labels that were assigned for the samples are presented in Table 1.

Table 1. Classification of the core samples obtained by drilling on the HMA mixtures (Karakaş et al., 2014; Karakas et al., 2015)

\begin{tabular}{ccc}
\hline Core samples & Mixture & Location \\
\hline SK & SBS-modified HMA & Roadside area \\
S & SBS-modified HMA & Wheel pass area \\
NK & Pure HMA & Roadside area \\
N & Pure HMA & Wheel pass area \\
\hline
\end{tabular}
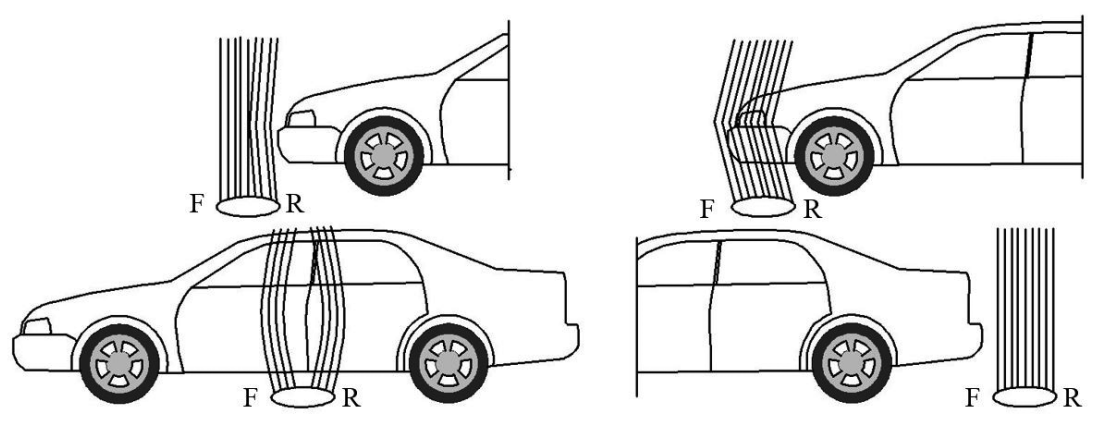

Figure 2. Magnetic imaging of vehicle movements by the sensors of the NC 100-200 device
Prediction of Mechanical Alteratıons in MultıLayer SBS-Modified Hot Mix Asphalt and Soil-Foundation Structure 
A series of laboratory tests were implemented to obtain the physical and mechanical properties of the samples taking from the targeted area (Fig. 3). In the scope of laboratory works, the samples were kept in the curing pool until they were exposed to Marshall tests. In addition, indirect tensile tests were performed to specify the properties of samples which were necessary to run a numerical analysis.

Field study and laboratory tests were conducted on the superstructure of the road for one year under traffic and environmental conditions. The core samples were obtained from the superstructure of the road by drilling in certain periods. Additionally, drilling works were performed, and natural ground layer properties were determined. B50/70 class binder, which constituted the building block of HMA, was used in the study for the road platform. The characteristics of the pure (neat) and SBS modified bitumen are presented in Tables 2 and 3, respectively.

a)

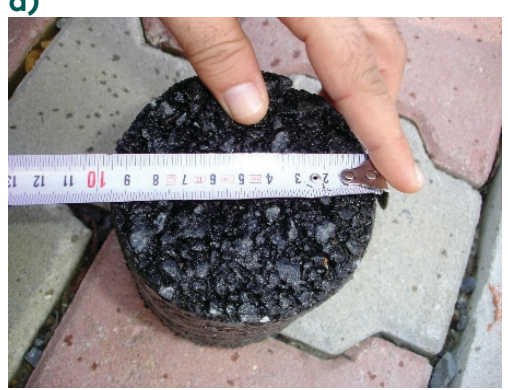

c)

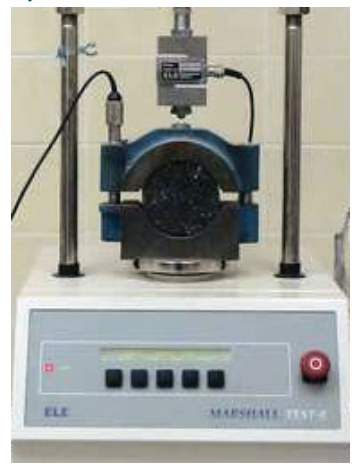

b)

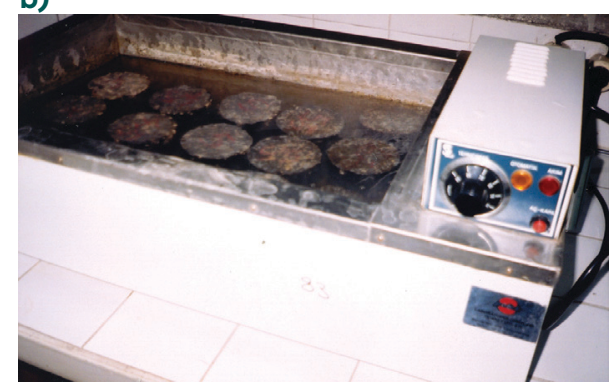

d)

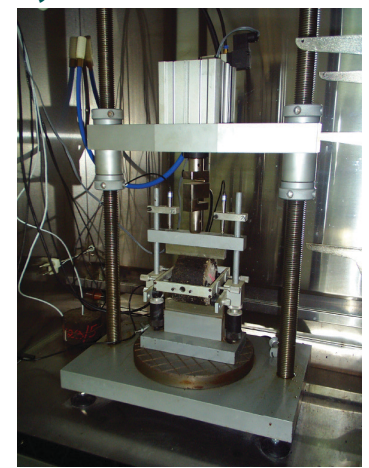

Figure 3. Experimental procedures for core samples: a) core sample diameter measurement, b) sample curing pool, c) Marshall test and, d) indirect tensile test 
Table 2. Properties of the neat bitumen

\begin{tabular}{ccc} 
Property & Test standard & Value \\
\hline Specific gravity, gr/cm & EN 15326 & 1.022 \\
Penetration, $25^{\circ} \mathrm{C}, 0.1 \mathrm{~mm}$ & EN 1426 61 \\
Softening point, ${ }^{\circ} \mathrm{C}$ & EN 1427 & 51.7 \\
Ductility, $25^{\circ} \mathrm{C}, \mathrm{cm}$ & EN 13589 & $>100$ \\
Fraas breaking point, ${ }^{\circ} \mathrm{C}$ & EN 12593 & -17 \\
\hline
\end{tabular}

Table 3. Properties of the SBS-modified bitumen

\begin{tabular}{ccc}
\hline Property & Test standard & Value \\
\hline Specific gravity, gr/cm & EN 15326 & 1.017 \\
Penetration, $0.1 \mathrm{~mm}, 100 \mathrm{~g}, 5 \mathrm{~s}$ & EN 1426 & B-68 \\
Softening point, ${ }^{\circ} \mathrm{C}$ & EN 1427 & 54.0 \\
Ductility, $25^{\circ} \mathrm{C}, \mathrm{cm}$ & EN 13589 & $>100$ \\
Fraas breaking point, ${ }^{\circ} \mathrm{C}$ & EN 12593 & -17.5 \\
\hline
\end{tabular}

It was observed that the SBS-modified bitumen was more sensitive in terms of softening point compared to the pure (neat) bitumen. However, pure bitumen was more sensitive in a low-temperature Frass breaking point. Accordingly, it was determined that the pure bitumen had a high softening point. In addition, temperature sensitivity values of the pure and SBS-modified bitumen met the limits set by the standards.

According to Ullidtz (1987), the Penetration Index (PI) values that are lower than -2 indicate that the bitumen is very sensitive to temperature while higher values than +2 indicate that it is less sensitive to temperature (Ullidtz, 1987). PI is determined by defining the standard penetration and softening points. In Eq. (1), $P 25$ represents the penetration at $25^{\circ} \mathrm{C}$, and $T \gamma N$ represents the softening point. In Eq. (2), the PI value of the pure bitumen was calculated as -0.015 , while the PI value of the SBS-modified bitumen was calculated as 0.249 . Accordingly, it was observed that the bitumen was sensitive to temperature in terms of $P I$ values.

$$
A=\frac{\log 800-\log P 25}{T \gamma N-25} .
$$

Ahmet Sertac 


$$
P I=\frac{20-500 A}{1+50 A} .
$$

For the screen analysis values of the aggregate used in the HMA, the aggregates used in the asphalt concrete pavement prepared with HMA were chosen as broken stone aggregate according to Type 2. In the aggregates in granular base layers, B-Type aggregates were chosen. Accordingly, it was determined that the aggregates in question met the conditions set by the standards, which were presented in Tables 4 and 5 .

Table 4. Aggregate gradation used in HMA

\begin{tabular}{ccc}
\hline Sieve size, mm & Passing percentage (gradation limits) & Used gradation \\
\hline 12.5 & 100 & 100 \\
9.5 & $90-100$ & 90.4 \\
4.75 & $63.5-72.0$ & 56.6 \\
2 & $44.5-53.0$ & 36.6 \\
0.425 & $22-28$ & 18.2 \\
0.18 & $12-16$ & 13.0 \\
0.075 & $7-10$ & 10.3 \\
\hline
\end{tabular}

Table 5. Aggregate gradation used in the granular base layer

\begin{tabular}{ccc}
\hline Sieve size, mm & Passing percentage (gradation limits) & Used gradation \\
\hline 50 & - & 100 \\
37.5 & 100 & 93 \\
25 & $70-100$ & 75 \\
19 & $60-92$ & 65 \\
9.5 & $40-75$ & 40 \\
4.75 & $30-60$ & 26 \\
2 & $20-45$ & 17 \\
0.425 & $10-25$ & 12 \\
0.075 & $0-12$ & 7 \\
\hline
\end{tabular}


The engineering properties of the aggregates used in HMA and granular base layers are presented in Tables 6 and 7, respectively. Additionally, it was observed that they met the criteria of the relevant standards.

Table 6. Physical properties of aggregates in HMA

\begin{tabular}{ccc}
\hline Property & Test standard & Value \\
\hline The bulk specific gravity of coarse aggregate & ASTM C127 & 2.733 \\
The bulk specific gravity of fine aggregate & ASTM C128 & 2.678 \\
The bulk specific gravity of mineral filler & ASTM D854 & 2.764 \\
Absorption coarse aggregate, \% & ASTM C127 & 0.38 \\
Absorption fine aggregate, \% & ASTM C127 & 0.88 \\
Los Angeles abrasion loss, \% & ASTM C-131 & 20.5 \\
Flatness Index, \% & BS 812 & 16.1 \\
Clay content, \% & AASHTO T176 & 53 \\
Angularity of coarse aggregate, \% & ASTM D-5851 & $97 / 96$ \\
Angularity of coarse aggregate, \% & AASHTO T304 & 49 \\
Flag and long grains & ASTM D-4791 & 3 \\
\hline
\end{tabular}

Table 7. Physical and mechanical properties of granular base aggregates

\begin{tabular}{ccc}
\hline Property & Test standard & Value \\
\hline Density & AASHTO T 88 & $2.30-2.35$ \\
Los Angeles abrasion loss, \% & AASHTO T 96 & 23 \\
Flatness Index, \% & BS 812 & 32 \\
Maximum dry unit weight & AASHTO T 89 & 2.30 \\
Optimum water content, \% & AASHTO T 89 & 5.9 \\
Liquid limit, \% & AASHTO T 89 & 25.5 \\
Plastic limit, \% & AASHTO T 89 & 14.9 \\
Plasticity Index, \% & AASHTO T 89 & 10.6 \\
Moisture gradient & AASHTO T 89 & 4.85 \\
Modified Proctor compaction, \% & AASHTO T 180 & 205 \\
Vibrating hammer, \% & BS 1377 & 210 \\
\hline
\end{tabular}

Prediction of Mechanical Alteratıons in MultıLayer SBS-Modified Hot Mix Asphalt and Soil-Foundation Structure 
To determine the design properties of HMA, the pure and SBSmodified asphalt concrete pavement samples obtained from the road platform were prepared by taking the aggregate gradation as the basis. The optimum bitumen rate in pure HMA was determined as $4.95 \%$, while the optimum bitumen rate in SBS-modified HMA was determined as $5.24 \%$. The properties of the design criteria are presented in Table 8 . Accordingly, it was observed that they provided the standards in question.

Table 8. Design properties of pure and SBS-modified HMA

\begin{tabular}{ccc}
\hline Definition & Values of Pure HMA & Values of SBS-modified HMA \\
\hline Optimum bitumen rate, \% & 4.95 & 5.24 \\
Practical specific gravity, & 2.415 & 2.411 \\
gr/cm & & \\
Marshall stability, kgf & 1222 & 1170 \\
Flow, mm & 3.03 & 3.58 \\
Aggregate void ratio, \% & 15.10 & 13.9 \\
Asphalt void ratio, \% & 73.93 & 75.4 \\
Air void ratio, \% & 3.94 & 3.10 \\
\hline
\end{tabular}

Table 9. Density, elasticity modulus, and Poisson's Ratio parameters in $\mathrm{N}$-type core samples

\begin{tabular}{|c|c|c|c|c|c|c|c|}
\hline Material & Layer & Depth, m & Months & $\begin{array}{l}\text { Equivalent } \\
\text { axle road, } t\end{array}$ & $\begin{array}{c}\text { Elasticity } \\
\text { modulus, MPa }\end{array}$ & $\begin{array}{l}\text { Poisson's } \\
\text { ratio }\end{array}$ & Density, $t / \mathrm{m}^{3}$ \\
\hline \multirow{4}{*}{ Pavement } & \multirow{4}{*}{1} & \multirow{4}{*}{0.10} & 1 & 451 & 2879 & \multirow{4}{*}{0.35} & 2.267 \\
\hline & & & 4 & 1328 & 3221 & & 2.272 \\
\hline & & & 8 & 2563 & 6824 & & 2.277 \\
\hline & & & 12 & 3091 & 8052 & & 2.284 \\
\hline $\begin{array}{c}\text { Granular } \\
\text { base }\end{array}$ & 2 & 0.20 & & & 150 & 0.30 & 2.30 \\
\hline Sub-base & 3 & 0.20 & & & 100 & 0.30 & 2.25 \\
\hline Filler & 4 & 1.50 & & & 80 & 0.30 & 2.16 \\
\hline Clay & 5 & 3.00 & & & 15 & 0.20 & 1.985 \\
\hline Limestone & 6 & 6.50 & & & 20684 & 0.40 & 2.60 \\
\hline Claystone & 7 & 19.0 & & & 3447 & 0.30 & 2.415 \\
\hline
\end{tabular}


Within the framework of the study, the traffic loads created by of Mechanical the vehicles on the road were measured on the road platform with the NC 200 Traffic Analysis device within certain intervals for one year. Furthermore, elasticity modulus and Poisson's ratio, which are Layer SBS-Modified Hot Mıx Asphalt and Soil-Foundation Structure parameters involved in the mechanical properties of different layers, are presented in Tables 9 and 10, respectively.

Table 10. Density, elasticity modulus, and Poisson's Ratio parameters in S-type core samples

\begin{tabular}{|c|c|c|c|c|c|c|c|}
\hline Material & Layer & Depth, m & Months & $\begin{array}{l}\text { Equivalent } \\
\text { Axle Load, t }\end{array}$ & $\begin{array}{c}\text { Elasticity } \\
\text { modulus, MPa }\end{array}$ & $\begin{array}{l}\text { Poisson's } \\
\text { ratio }\end{array}$ & $\begin{array}{c}\text { Density } \\
t / m^{3}\end{array}$ \\
\hline \multirow{5}{*}{ Pavement } & \multirow{5}{*}{1} & \multirow{5}{*}{0.10} & 1 & 451 & 3105 & \multirow{5}{*}{0.35} & 2.271 \\
\hline & & & 4 & 1328 & 4089 & & 2.287 \\
\hline & & & & & & & \\
\hline & & & 8 & 2563 & 8058 & & 2.289 \\
\hline & & & 12 & 3091 & 9636 & & 2.288 \\
\hline $\begin{array}{c}\text { Granular } \\
\text { base }\end{array}$ & 2 & 0.20 & & & 150 & 0.30 & 2.300 \\
\hline Sub-base & 3 & 0.20 & & & 100 & 0.30 & 2.250 \\
\hline Filler & 4 & 1.50 & & & 80 & 0.30 & 2.160 \\
\hline Clay & 5 & 3.00 & & & 15 & 0.20 & 1.985 \\
\hline Limestone & 6 & 6.50 & & & 20684 & 0.40 & 2.600 \\
\hline Clay stone & 7 & 19.0 & & & 3447 & 0.30 & 2.415 \\
\hline
\end{tabular}

\subsection{Numerical Model}

The finite element (FE) approach is a numerical solution method used frequently in engineering practices to examine the continuous medium problems by evaluating them after dividing them into a certain number of elements. According to this method, the solution is obtained by dividing a medium or an object by finite elements and producing the rigidity matrix for each element and integrating the solutions for all elements. The numerical solutions of the differential equations that express the mechanical behaviour of the system in question are provided in a matrix format. In general, bigger matrices appear for geometrical 
applications that require multiple elements. Solving such problems, the necessary linear algebraic operations are performed via computers.

In this study, a finite element model of the entire road structure was prepared to simulate the effects of traffic and environmental conditions. The superstructure of the road and the natural ground layers were considered solid elements, which had linearly elastic and isotropic behaviours. Young's modulus and Poisson's ratio, which are essential mechanical properties of the layers, were obtained experimentally. The mechanical properties of layers, asphalt pavement, the base, sub-base, filling, limestone, claystone, and clay in the structure, are presented in Tables 9 and 10. Geometric and mesh models of the road section in question, including the superstructure and natural ground layers, are demonstrated in Figs. 4 and 5, respectively. FE models, which were designed according to geometric properties presented in Fig. 4, included 140020 elements and 749951 nodes on average (Fig. 5). A number of elements and nodes were specified carefully to provide high accuracy and consistency with real-world conditions and to avoid high computational load.

The FE models were designed to be examined by labelling them as the Pure Wheel Pass Area (N), the Pure Road Side Area (NK), the SBSModified Wheel Pass Area (S), and the SBS-modified Road Side Area (SK). Various models were prepared for various periods, which covered the 1st, 4th, 8th, and 12th months according to the changes in exposure to the traffic and the environmental effects on the superstructure and natural ground layers. In the analyses, the $\mathrm{N}$ and $\mathrm{S}$ series of $\mathrm{FE}$ models were implemented to simulate the effects of external loads that originated from the passes of the vehicles. Furthermore, the analyses of the roadsides samples of the NK and SK series solely covered the weights of the samples due to gravity.

a)

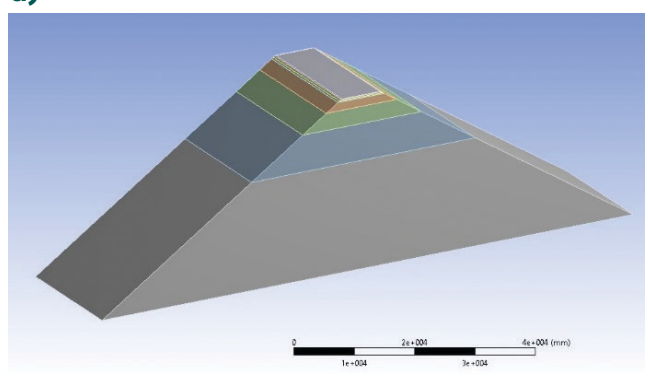

b)

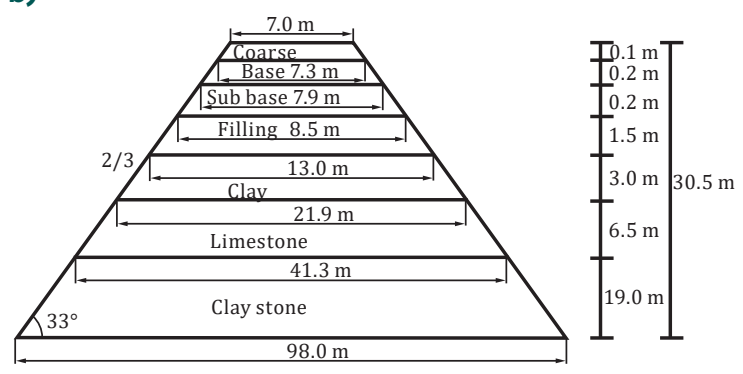

Figure 4. Road structure: a) geometry of model and b) the superstructure and natural ground layers within the body of structure 
The layers in FE models were assumed to be bounded (no separation and slip) with the adjacent layers by considering the adherence properties of the materials and ignoring relatively small movements.

The external forces to be considered in FE models were obtained from the data received during the experiments for $\mathrm{N}$ and $\mathrm{S}$ series. In the FE analysis of the $\mathrm{N}$ and $\mathrm{S}$ series, the cumulative traffic loads were used to calculate loads within $1.5 \mathrm{~s}$ of each period because the passing or contact duration of vehicle wheel loads on asphalt pavement was $1.5 \mathrm{~s}$. For all FE models, this cumulative and external force was considered as a static load. Tables 9 and 10 present the loads that were considered in FE models.

Road superstructure and natural ground layer are considered to be the layers of fill. Therefore, a trapezoid shape was widely adopted for road designs in the numerical works. Since a trapezoid structure was employed to simulate and quantify the performance of asphalt pavement, the whole geometry, including the layers, was modelled using a trapezoid shape (McLean, 2010; Karakas \& Ortes, 2017). The superstructure and natural ground layers of the roads consisted of seven layers presented in Fig. 4. The natural ground layer covered the filling, clay, limestone, and claystone formations, while the superstructure covered the sub-base, base, and coarse layers.

Numerical analyses were performed by using the parameters obtained from the empirical methods to determine the deformation and stress behaviours of the structure, which consisted of the

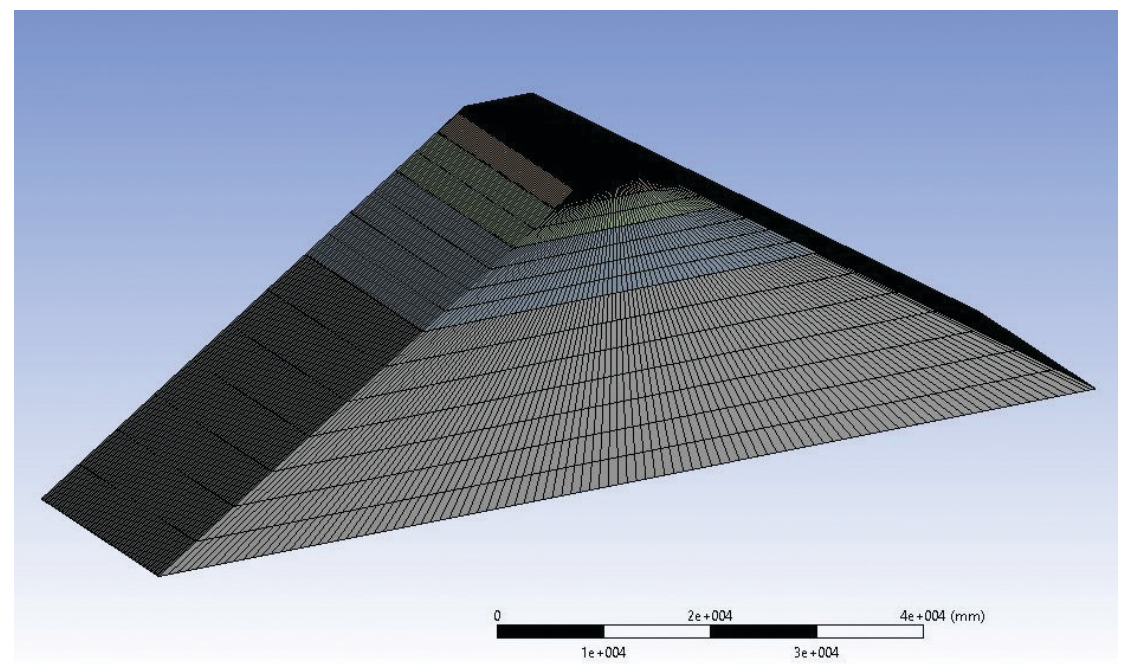

Figure 5. Perspective view of the mesh model
Prediction of Mechanical Alteratıons in MultıLayer SBS-Modified Hot Mix Asphalt and Soil-Foundation Structure 
superstructure and ground layers, under traffic and environmental conditions within one year. In the numerical analyses, it was aimed to simulate the actual field conditions of the road structure by considering the geometry of the targeted field and employing a series of parameters, such as the elasticity modulus, Poisson's ratio, density, and equivalent axle load of the core samples that were obtained at different periods by drilling.

In the literature, a notable number of experimental studies considered various approaches while evaluating the behaviour of road structures under various conditions.

Burland et al. (1977) examined the effects of non-linearity, nonhomogeneity, and anisotropy by considering various types of grounds. In their study, the researchers reported that the Boussinesq approximation yielded the stress distribution of the ground layers under loaded areas in an acceptable way. In a study conducted by Keskin et al. (2008), the researchers investigated the additional vertical stresses led by Uniform Loaded Square Bases on a sandy ground in empirical and numerical analyses and compared them with the results obtained with Boussinesq approximation. The ground was modelled by using 2-dimensional axial symmetry in the study applying the finite elements method (FEM) for the comparisons between empirical, numerical, and theoretical results. Accordingly, it was observed that the results were consistent with each other.

Although various methods were used in solving the ground problems, one of these methods that considered the theory of elasticity was the one suggested by Boussinesq. In the analytical solution suggested by Boussinesq (1885), the stress problem caused due to a single load that influenced the surface in a linear, elastic, homogeneous, isotropic, semiinfinite medium was solved.

Based on this solution, the additional and vertical stress values caused by a single load, $Q$, at any depth, $z$, in the ground and on the lateral distance, $r$, is demonstrated as $\Delta \sigma z$ in Eq. (3).

$$
\Delta \sigma_{z}=\frac{3}{2 \Pi}\left[\frac{1}{1+(r / z)^{2}}\right]^{5 / 2} \frac{Q}{z^{2}},
$$

where the additional vertical stress at a point at any depth, $z$, under any corner of the uniformly distributed and loaded rectangular area is as the single-load expression of Newmark Newmark (1935) and Boussinesq (1885) in Eq. (4). 


$$
\begin{aligned}
\Delta \sigma_{z}= & \frac{q}{4 \Pi} \frac{2 B L z\left(B^{2}+L^{2}+2 z^{2}\right)}{\left(B^{2}+z^{2}\right)\left(L^{2}+z^{2}\right) \sqrt{z^{2}+B^{2}+L^{2}}}+ \\
& +\frac{q}{4 \Pi} \tan ^{-1}\left(\frac{2 B L z \sqrt{z^{2}+B^{2}+L^{2}}}{-B^{2} L^{2}+z^{2}\left(B^{2}+L^{2}\right)+z^{4}}\right)
\end{aligned}
$$

Westergaard performed Eq. (5) to obtain the additional vertical stress value, which occurred under a uniform rectangular loaded area (Westergaard, 1938).

$$
\Delta \sigma_{z}=q \frac{1}{2 \Pi}\left[\cot ^{-1} \sqrt{\left(\frac{1-2 \mu}{2-2 \mu}\right)\left(\frac{1}{m^{2}}+\frac{1}{n^{2}}\right)+\left(\frac{1-2 \mu}{2-2 \mu}\right)^{2}\left(\frac{1}{m^{2} n^{2}}\right)}\right]
$$

Here, $\mu$ represents the Poisson's ratio while $m$ and $n$ represent the coefficients depending on the geometry.

\section{Results and discussion}

In the study, all the Finite Element Models representing the physical identities of multi-layer asphalt structures included 140020 elements and 749951 nodes on average. The type of element was chosen as a quadratic tetrahedral element. Moreover, layers that were critical components of the superstructure of the road were assumed to demonstrate linearly elastic and isotropic behaviours in terms of mechanical properties in addition to having homogeneous material properties. Furthermore, to assign the boundary conditions in the models, the bottom and side faces of the models were fixed. Therefore, none of the displacements and rotations were allowed according to the assumption that the deformations that occurred in the under most layer, the limestone layer, were negligible. Additionally, the interface between the neighbouring layers was also assumed to be perfectly bonded, which meant there were no separations or sliding between the layers. The forces of traffic loads were applied to the top surface in the models and the magnitudes of the forces for FEM models were calculated over the equal axial loads caused by the vehicles that used the road. The types and numbers of the vehicles that passed on the road were determined by using the Field Testing Device in various periods for one year. Additionally, the vehicle records for the same year were included in the analyses while the equivalent axle single load numbers were determined.

By considering the maximum load values in $0.274 \mathrm{~s}$ and the unloading values in $1.5 \mathrm{~s}$ on the wheel pass areas of the vehicles on asphalt
Ahmet Sertac

Karakas,

Faruk Ortes

Prediction

of Mechanical

Alteratıons in Multı-

Layer SBS-Modified

Hot Mix Asphalt

and Soil-Foundation

Structure 
pavements, the maximum load repetition numbers in certain periods were determined in addition to calculating the elasticity modulus values.

Through the analyses of the FEM models, the horizontal and vertical deformations that occurred in the superstructure and on the layers within one year, and the Von Mises stress values were determined. According to the four different types of pavements in the study, N, NK, $\mathrm{S}$, and SK-types, the total and maximum Von Mises stresses at the end of the year are presented in Figs. 6 and 7, respectively.

Asphalt design and application were performed for a road under the exposure of traffic and the change of weather conditions which were also measured for different time periods. Several core samples were obtained from the road to determine physical and mechanical properties through laboratory tests. Finite element models of the structures were created employing parameters obtained from the laboratory investigations, and a series of simulations to reveal the essential behaviour of the structure were performed. As a result of the computations, stress and deformation characteristics for unmodified and SBS-modified asphalt layers were predicted through calculations. Furthermore, the mechanical behaviours of layers below the road superstructure exposed to the influence of traffic and environmental conditions were also investigated with the help of simulations. The simulations for road superstructure and natural ground layers were repeated to represent different time periods (i.e., $1 \mathrm{st}$, 4th, 8th, and 12th months) and mathematical models were created
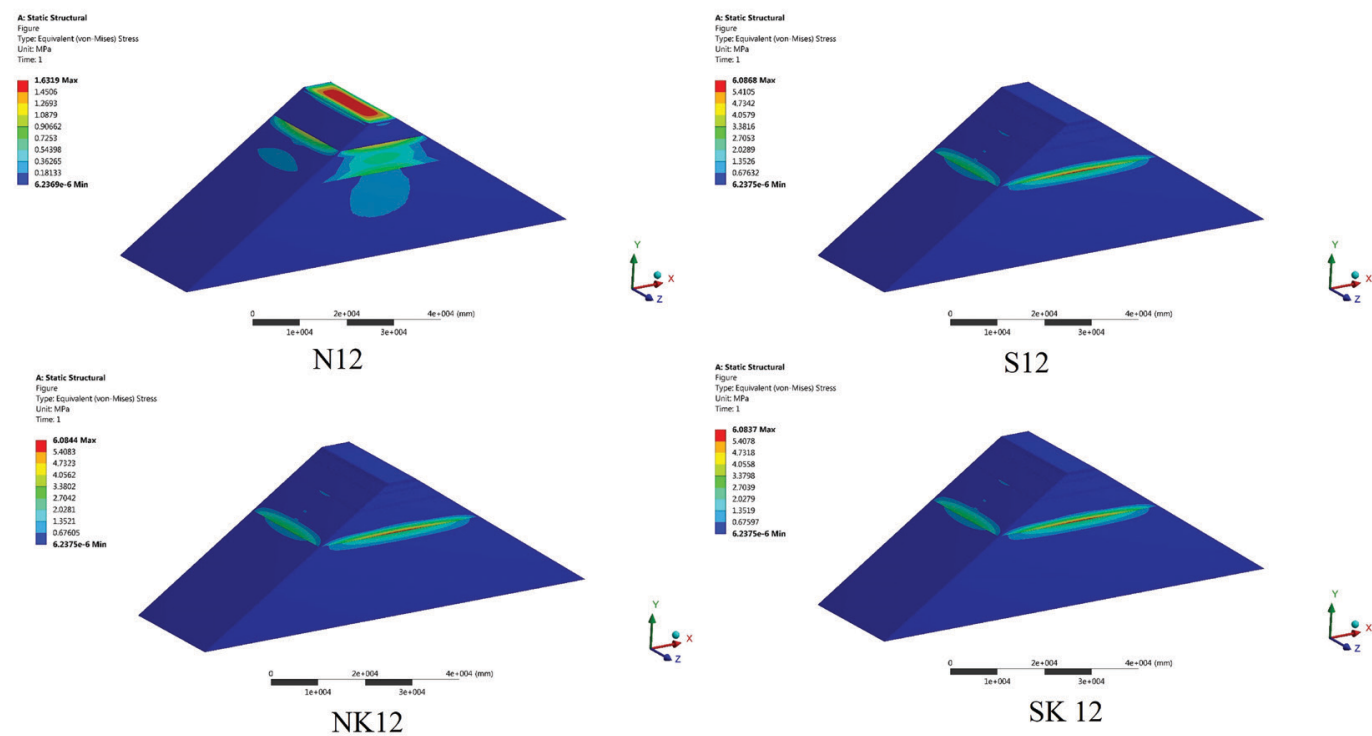

Figure 6. Von Mises Stresses on FEM models for the whole structure 
with regression to determine whether the model was convenient for experimental studies. By doing this process, it can be checked whether there is a strong relationship and correlation between finite element analysis and experimental results. of Mechanical

Alteratıons in MultıLayer SBS-Modified Hot Mix Asphalt

and Soil-Foundation

Structure
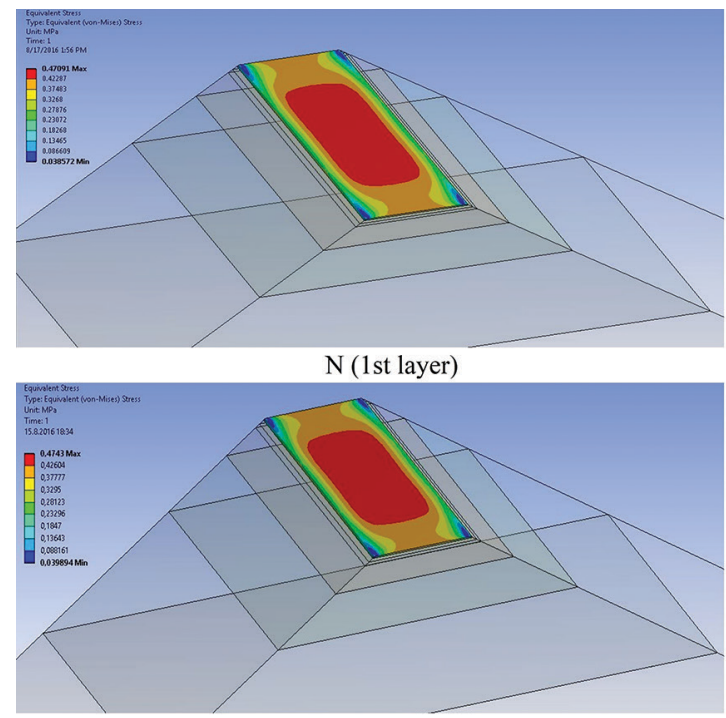

NK (1st layer)

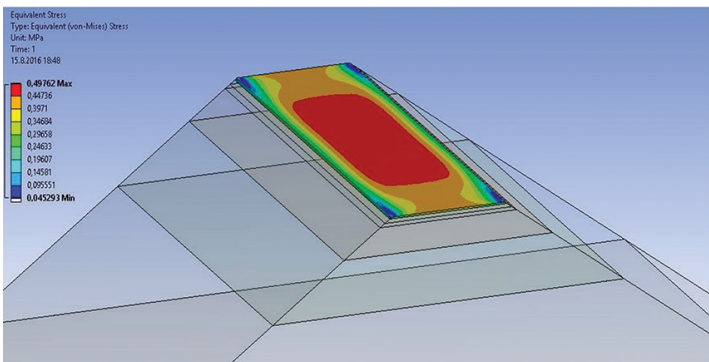

S (1st layer)

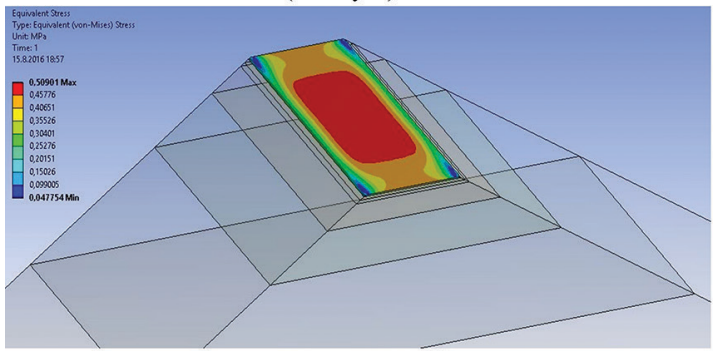

SK (1st layer)

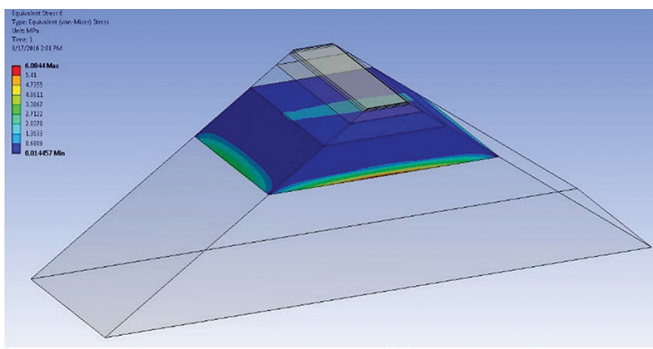

$\mathrm{N}$ (max. $6^{\text {th }}$ layer)

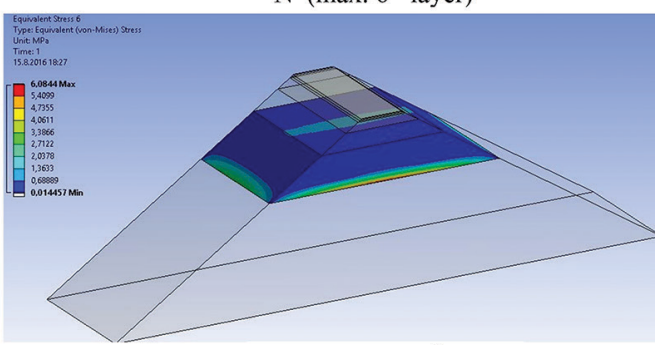

NK 12 (max. $6^{\text {th }}$ layer)

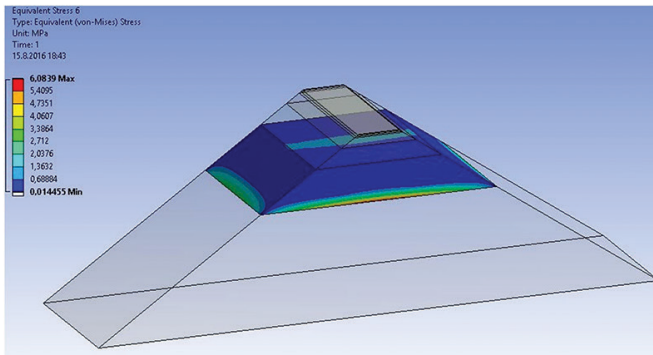

S 12 (max. $6^{\text {th }}$ layer)

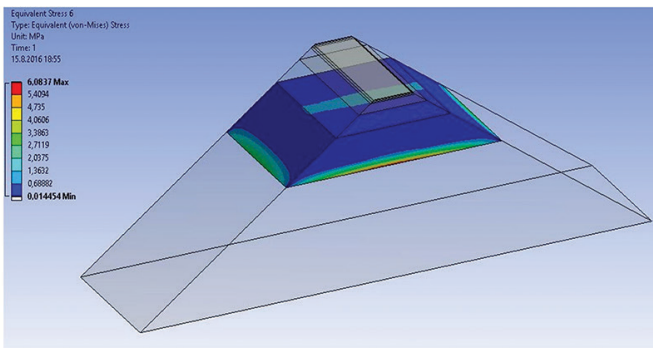

SK 12 (max. $6^{\text {th }}$ layer)

Figure 7. Von Mises Stresses on FEM models for the 1st layer (pavement) and max 6th layer 
Examining Fig. 6, it was observed that the total Von Mises stress values were intensified in the 6th layer and had similar properties with each other in all types of road pavements.

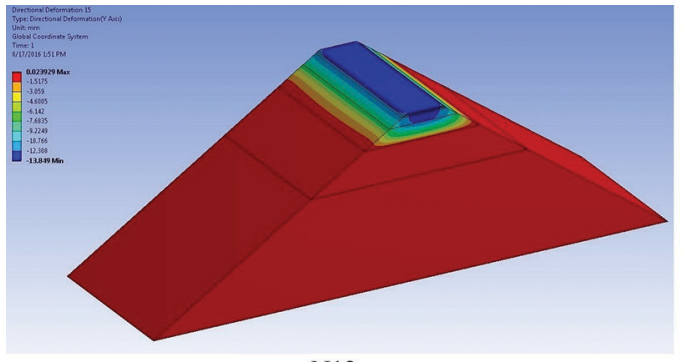

$\mathrm{N} 12$

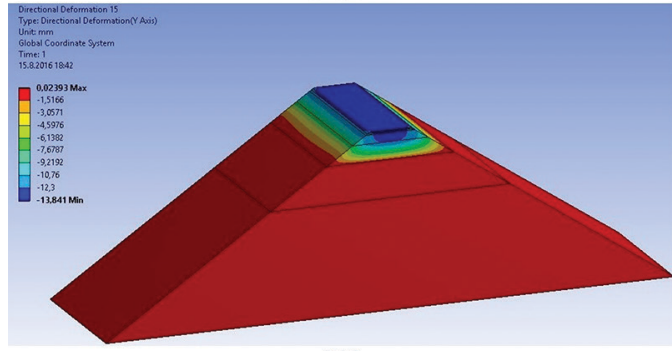

S12
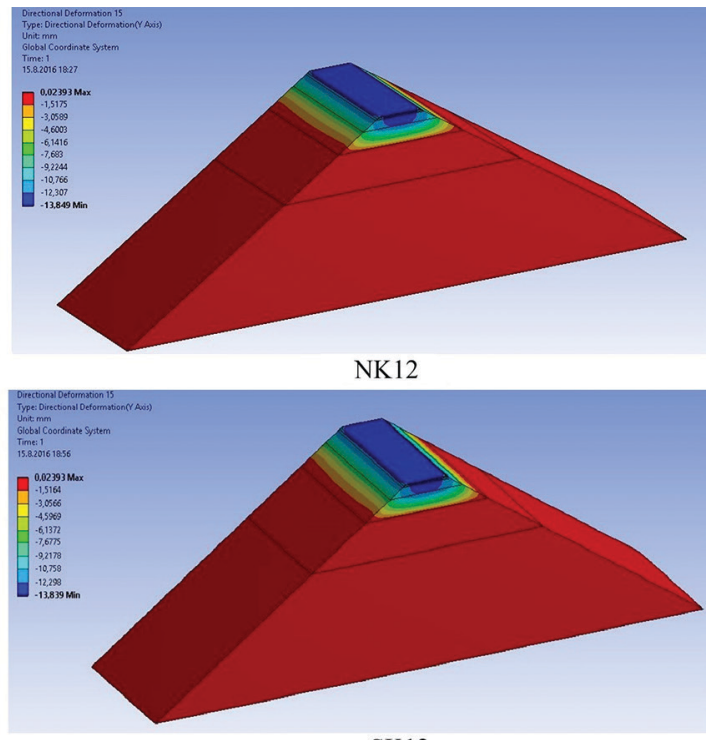

SK12

Figure 8. Vertical deformations on FEM models for all the layers
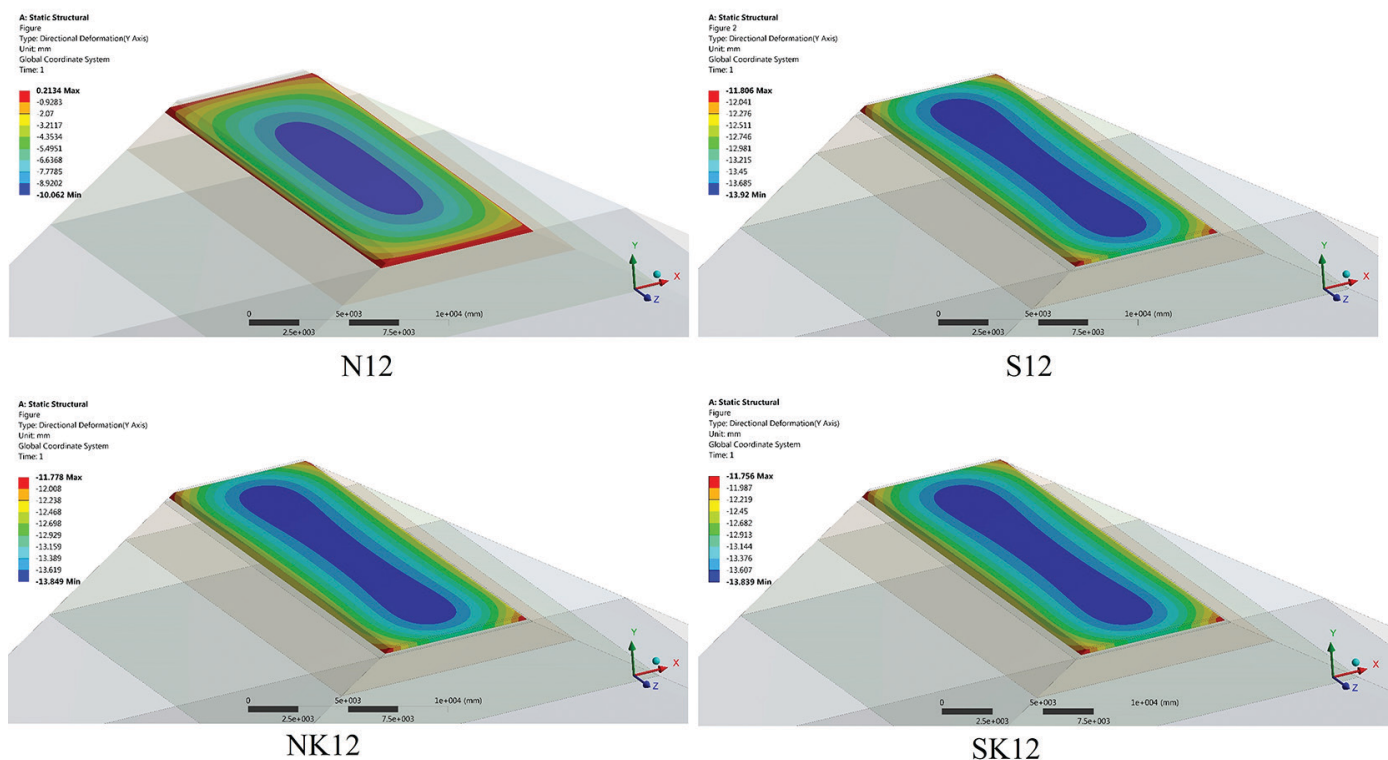

Figure 9. Vertical deformations on FEM models for the first layers 
Evaluating Fig. 7, it was observed that the maximum Von Mises of Mechanical Alteratıons in Multıstress values were in the 6th layer and had similar properties with each other in all of the road superstructure types in the 6th layer. It was concluded that the stresses intensified in the middle points because of the maximum loading effect at 0.274 seconds and the unloading effect in 1.5 seconds, which were caused by equivalent axial loads due to the wheel pass on the surface of the pavement, and the effect was decreased towards the sides. In the analyses, it was observed that the Von Mises stress values were slightly higher in S and SK-Type pavements compared to $\mathrm{N}$ and NK-type pavements. The FEM model of the total vertical deformations and maximum vertical deformations observed for one year in terms of all types of pavements are presented in Figs. 8 and 9, respectively.

According to Fig. 8, it was observed that the total vertical deformations demonstrated an increase by diffusing as a pressure bulb towards the lower layers. Since the incoming load was transferred to the sub-layers, it was determined that there were increases in the deformation from the sub-ground layers towards the natural ground layer, especially from the 5 th and 6 th layers.

All the deformations in all types of road superstructures were observed to have close values to each other.

When Fig. 9 was examined, it was observed that the highest vertical deformations were in the pavement layers that were exposed to the highest vehicle load. Higher deformations were determined in Types $\mathrm{S}$ and $\mathrm{N}$, which were wheel pass areas, compared to Types SK and

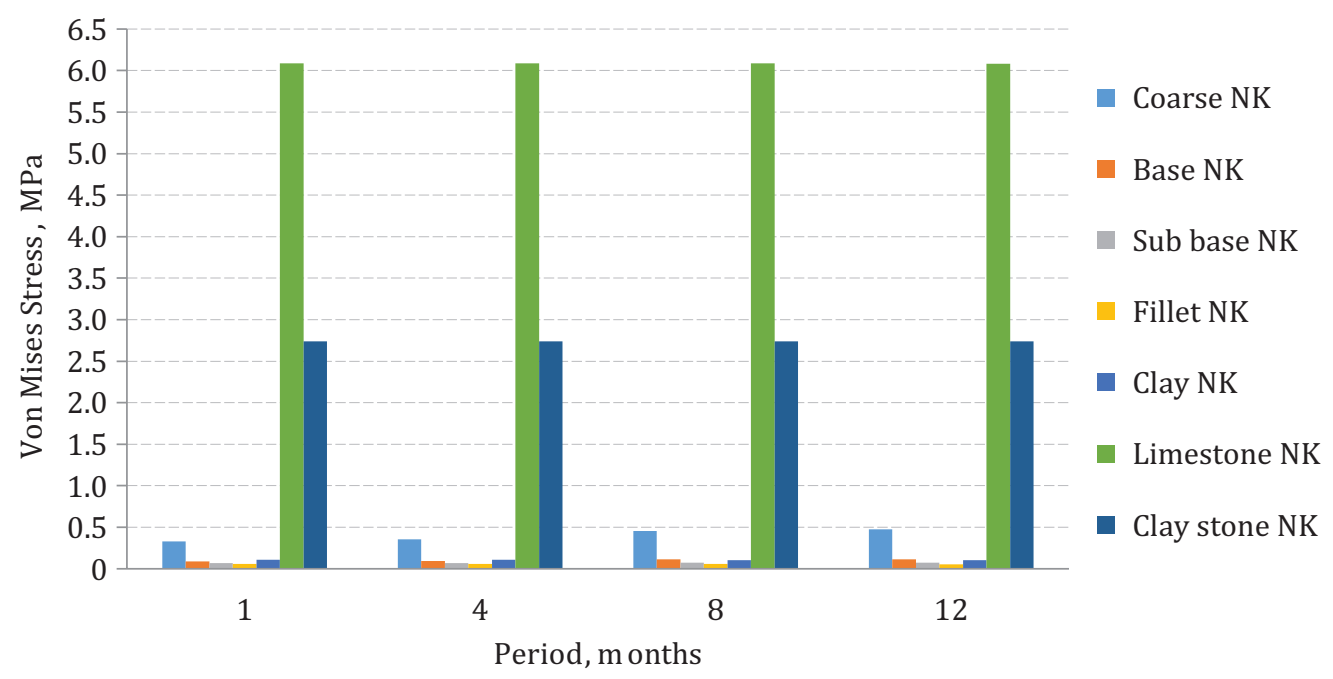

Figure 10. Von Mises stress-time changes of the layers for NK-Type 
$\mathrm{NK}$, which were roadside areas. It was determined that there were fewer deformations in Type S and Type SK pavements, which had SBS modification compared to Type $\mathrm{N}$ and Type NK, which did not contain additives.

The changes in the Von Mises stresses on the superstructure and subground layer within one year are presented in Figs. 10-13, respectively.

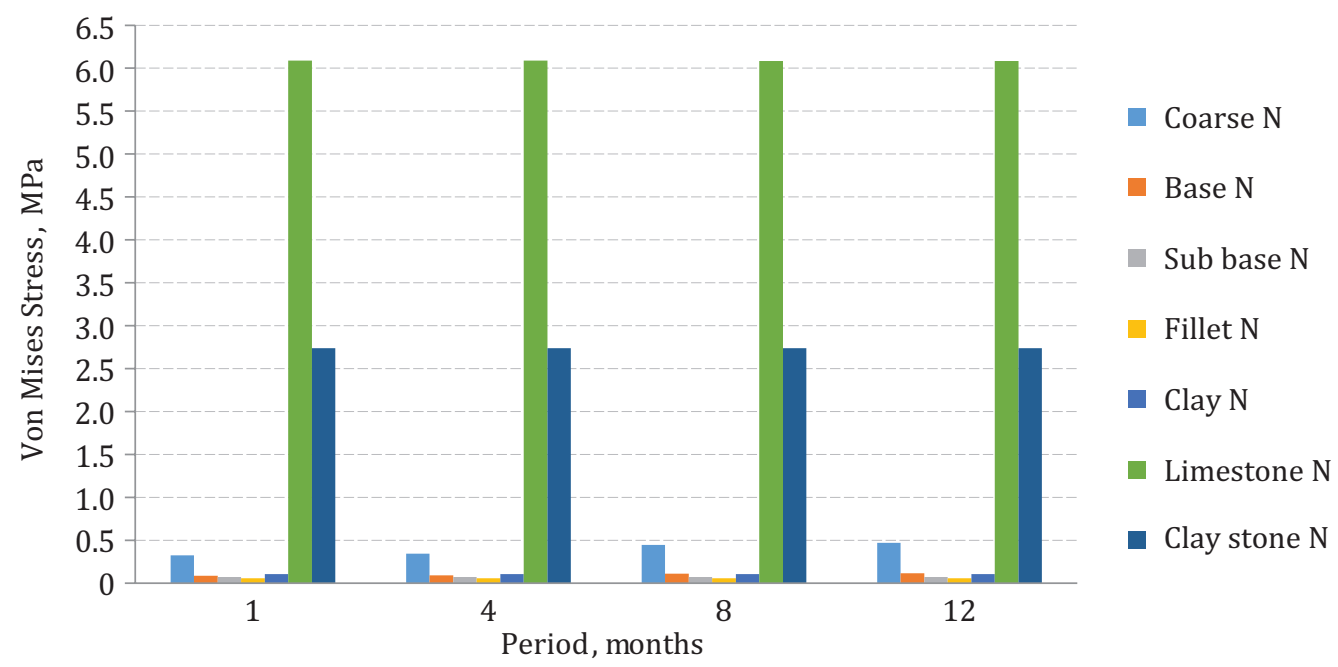

Figure 11. Von Mises stress-time changes of the layers for N-Type

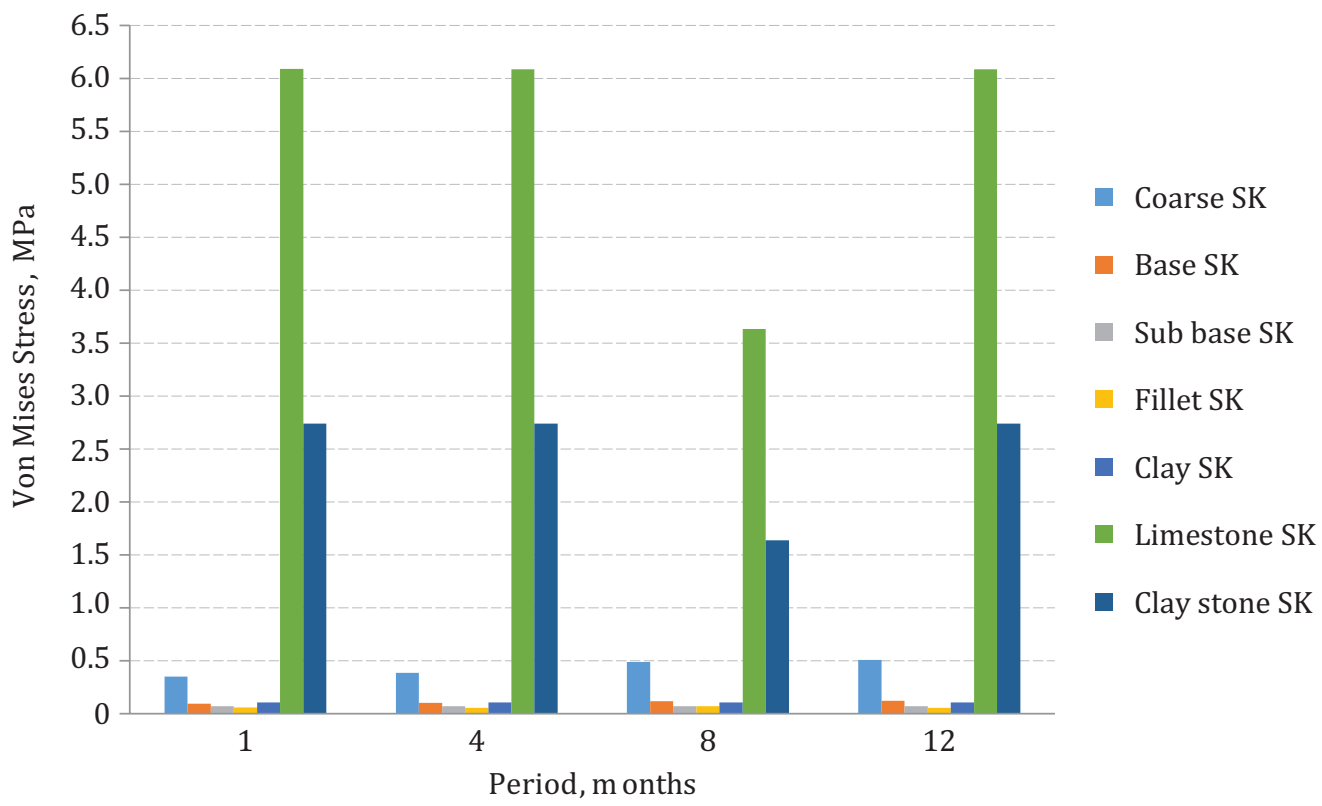

Figure 12. Von Mises stress-time changes of the layers for SK-Type 
Examining Figs. 10-13, it was found out that the highest Von Mises stress values in the superstructure and natural ground layers in all types of the pavements were in the 6th (clay), 7th (limestone) and in the pavement layers, respectively. The stresses in N, NK, S, and SK-Type asphalt pavement layers were increased throughout one year, and there were no significant increases in the stress values of the other layers. The increase in the Von Mises stress values in road-side area pavement layers between the 1st and 12th months was $43.59 \% \mathrm{MPa}$ for NK-Type pavements, $45.64 \% \mathrm{MPa}$ in SK-Type pavements, and $44.31 \% \mathrm{MPa}$ in wheel pass areas for N-Type pavements. By using additives, increases were achieved in roadside areas at a rate of $7.32 \%$, and in wheel pass areas at a rate of $5.67 \%$ within one year. In the 12th month, in roadside areas, Von Mises stress values were increased in pure NK-Type compared to the pure $\mathrm{N}$ asphalt pavement type at a rate of $0.72 \%$ in wheel pass areas, and in additive types, the Von Mises stress values were increased at a rate of $2.28 \%$ compared to the ones with additives, the S-Type of the SK-Type. This resulted from the over-pressurizing of the roads towards the sides due to the cross-fall inclination of the road, using curbs on roadsides, and the cars using this area as a parking space. The maximum Von Mises stress value in the 6th layer was determined as $6.1 \mathrm{MPa}$, and as 2.7 $\mathrm{MPa}$ in the 7 th layer.

Table 11 presents the function and regression analyses of the relationship between the asphalt and soil layers of the road with Von Mises time. According to Table 11, the $R^{2}$ values of Von Mises stress in all of the road superstructures and natural ground layers within one year were generally close to one, and it was determined that numerical analyses supported the empirical analyses, which indicated a strong relationship.

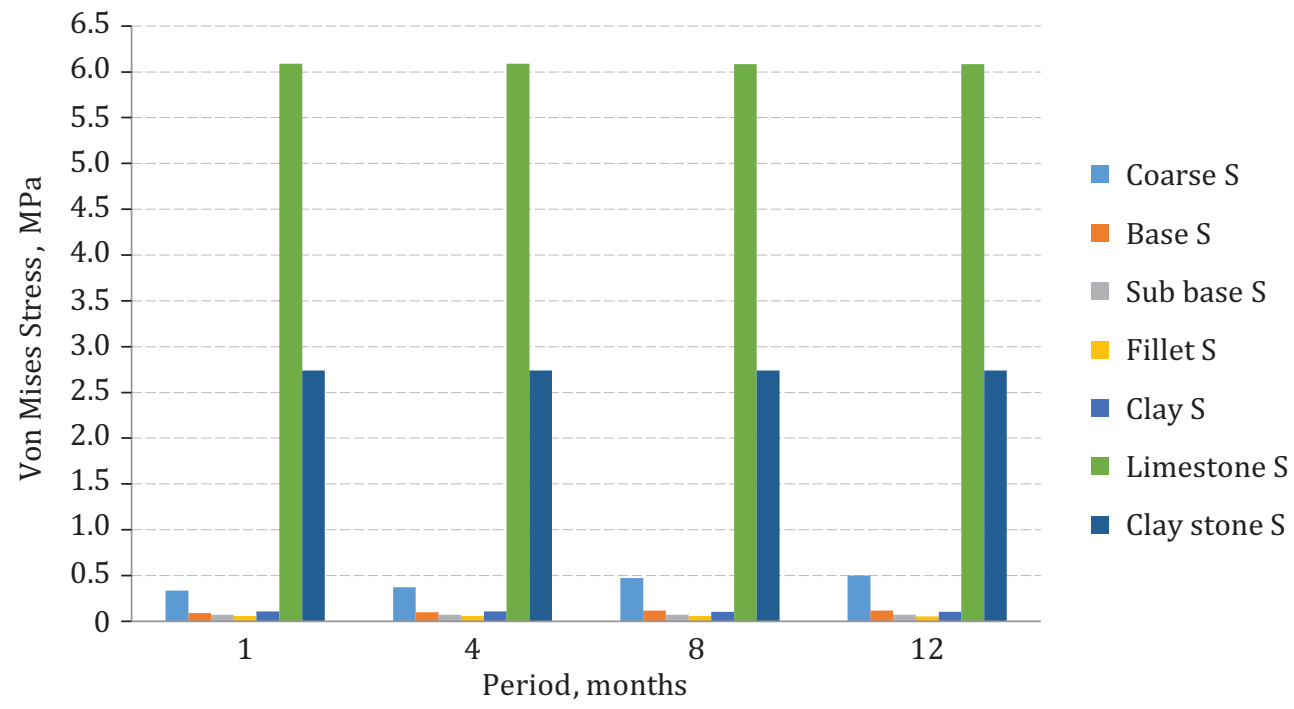

Figure 13. Von Mises stress-time changes of the layers for S-Type
Prediction of Mechanical Alterations in MultıLayer SBS-Modified Hot Mix Asphalt and Soil-Foundation Structure 
Table 11. Function and regression analyses of the relationship between the superstructure and soil layers of the road with Von Mises Time

\begin{tabular}{|c|c|c|c|}
\hline Layer & Regression models & Mathematical models & $R^{2}$ \\
\hline \multirow{4}{*}{ Coarse } & SK & $y=-0.0045 x^{2}+0.0806 x+0.2659$ & 0.9382 \\
\hline & $\mathrm{S}$ & $y=-0.0029 x^{2}+0.0723 x+0.2606$ & 0.9531 \\
\hline & NK & $y=-0.0014 x^{2}+0.0599 x+0.2645$ & 0.9298 \\
\hline & $\mathrm{N}$ & $y=0.0022 x^{2}+0.0427 x+0.2728$ & 0.9085 \\
\hline \multirow{4}{*}{ Base } & SK & $y=-0.0007 x^{2}+0.0135 x+0.0792$ & 0.962 \\
\hline & $\mathrm{S}$ & $y=-0.0009 x^{2}+0.015 x+0.075$ & 0.9548 \\
\hline & NK & $y=-0.0005 x^{2}+0.0125 x+0.0757$ & 0.9308 \\
\hline & $\mathrm{N}$ & $y=0.0002 x^{2}+0.0092 x+0.0771$ & 0.9055 \\
\hline \multirow{4}{*}{ Sub-base } & SK & $y=-3 E-05 x^{2}+0.0008 x+0.0697$ & 0.9952 \\
\hline & $\mathrm{S}$ & $y=-0.0001 x^{2}+0.0013 x+0.069$ & 0.9619 \\
\hline & NK & $y=-7 E-05 x^{2}+0.0011 x+0.069$ & 0.9352 \\
\hline & $\mathrm{N}$ & $y=-1 E-05 x^{2}+0.0009 x+0.0691$ & 0.9039 \\
\hline \multirow{4}{*}{ Fillet } & SK & $y=-0.004 x^{2}+0.021 x+0.0377$ & 0.3839 \\
\hline & $\mathrm{S}$ & $y=5 E-05 x^{2}-0.0007 x+0.058$ & 0.9541 \\
\hline & NK & $y=3 E-05 x^{2}-0.0007 x+0.058$ & 0.9286 \\
\hline & $\mathrm{N}$ & $y=-2 E-06 x^{2}-0.0005 x+0.0579$ & 0.9010 \\
\hline \multirow{4}{*}{ Clay } & SK & $y=0.0003 x^{2}-0.002 x+0.1093$ & 0.8050 \\
\hline & $\mathrm{S}$ & $y=6 E-05 x^{2}-0.001 x+0.1085$ & 0.9533 \\
\hline & NK & $y=4 E-05 x^{2}-0.0009 x+0.1085$ & 0.9283 \\
\hline & $\mathrm{N}$ & $y=-5 E-06 x^{2}-0.0006 x+0.1084$ & 0.9021 \\
\hline \multirow{4}{*}{ Limestone } & SK & $y=0.6125 x^{2}-3.3089 x+9.1517$ & 0.4004 \\
\hline & $\mathrm{S}$ & $y=1 \mathrm{E}-04 x^{2}-0.002 x+6.0901$ & 0.9500 \\
\hline & NK & $y=1 E-04 x^{2}-0.0019 x+6.0904$ & 0.9219 \\
\hline & $\mathrm{N}$ & $y=-2 E-05 x^{2}-0.0013 x+6.0899$ & 0.8926 \\
\hline \multirow{4}{*}{ Claystone } & SK & $y=0.2754 x^{2}-1.4875 x+4.1168$ & 0.4003 \\
\hline & $\mathrm{S}$ & $y=5 E-05 x^{2}-0.0008 x+2.7403$ & 0.9532 \\
\hline & NK & $y=5 E-05 x^{2}-0.0008 x+2.7404$ & 0.9141 \\
\hline & $\mathrm{N}$ & $y=-3 E-05 x^{2}-0.0004 x+2.7401$ & 0.8863 \\
\hline
\end{tabular}

Polynomial is a function type for all the models 
The changes in the vertical and lateral deformation on the superstructure and sub-ground layer within one year are presented in Figs. 14-21, respectively.

Considering the vertical stresses in all of the layers in Figs. 14-17, it was observed that the vertical deformation values in the pavement, base sub-base, and filler layers were higher, and there were not many changes in the vertical deformation values within one year. The deformations in
Prediction of Mechanical Alteratıons in MultıLayer SBS-Modified Hot Mıx Asphalt and Soil-Foundation Structure

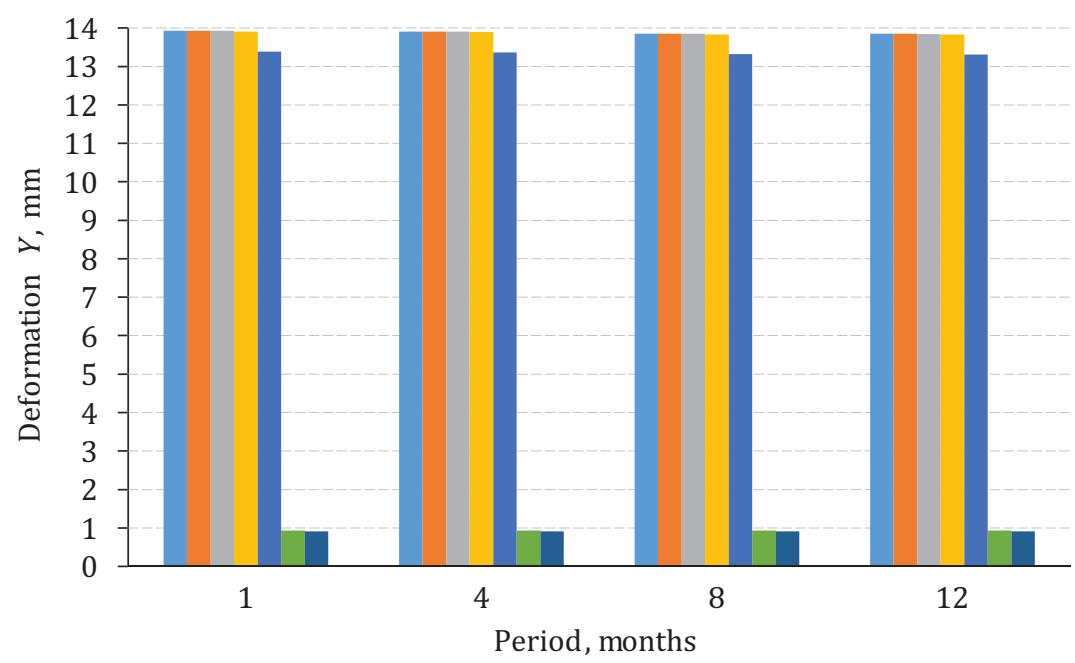

Figure 14. Vertical deformation (y)-time changes of the layers for NK type

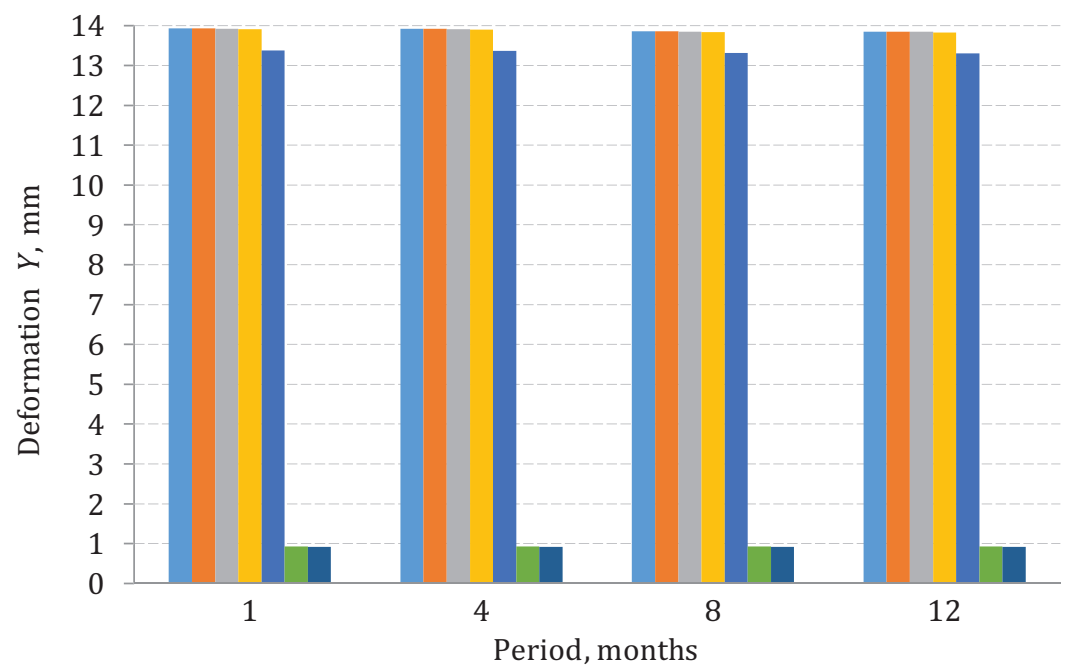

Figure 15. Vertical deformation (y)-time changes of the layers for $\mathrm{N}$ type
Coarse NK

Base NK

Sub base NK

Fillet NK

- Clay NK

- Limestone NK

- Clay stone NK
- Coarse N

- Base N

- Sub base N

- Fillet N

- Clay $\mathrm{N}$

- Limestone $\mathrm{N}$

- Clay stone $\mathrm{N}$ 
the N-NK-Types had nearly the same values, which were $13.93 \mathrm{~mm}$ in the 1st month, and $13.85 \mathrm{~mm}$ in the 12th month in the pavement and base layers, $13.93 \mathrm{~mm}$ in the 1st month, and $13.84 \mathrm{~mm}$ in the 12th month in the sub-base layers, $13.91 \mathrm{~mm}$ in the $1 \mathrm{st}$ month, and $13.83 \mathrm{~mm}$ in the 12th month in filler layers. In the S-Type pavement and base layers, they were determined to be $13.92 \mathrm{~mm}$ in the 1st month and $13.84 \mathrm{~mm}$ in the 12th month, in the sub-base layers they were $13.92 \mathrm{~mm}$ in the 1st month

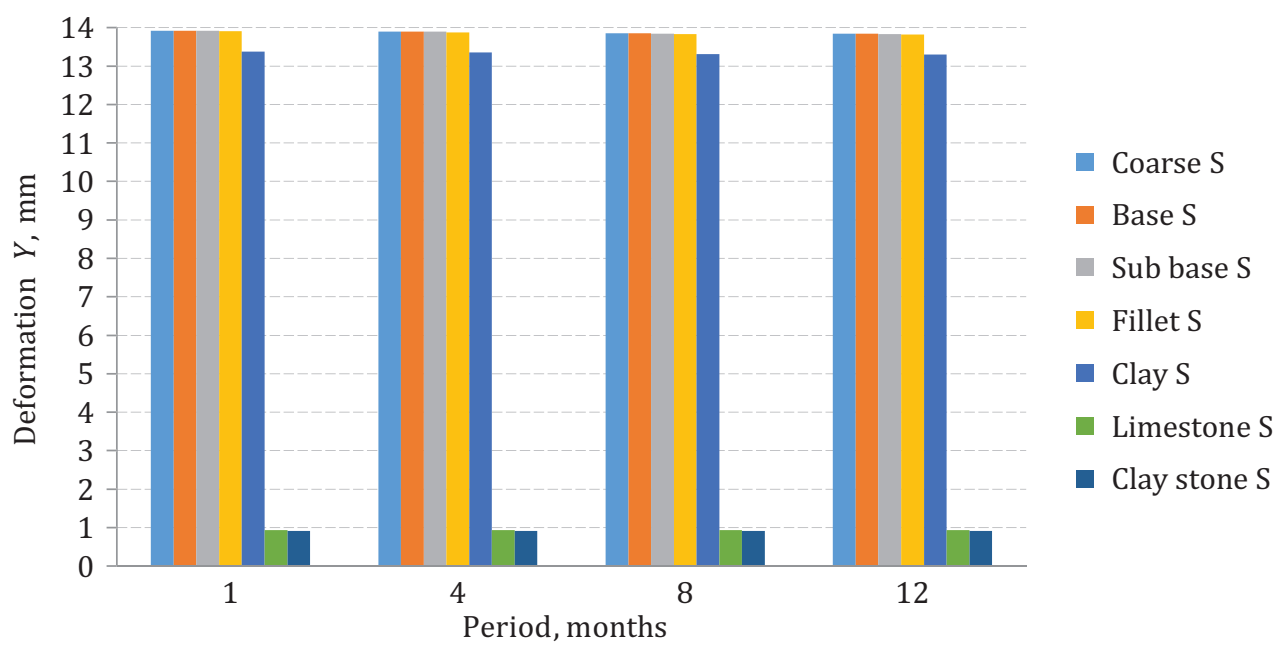

Figure 16. Vertical deformation (y)-time changes of the layers for SK type

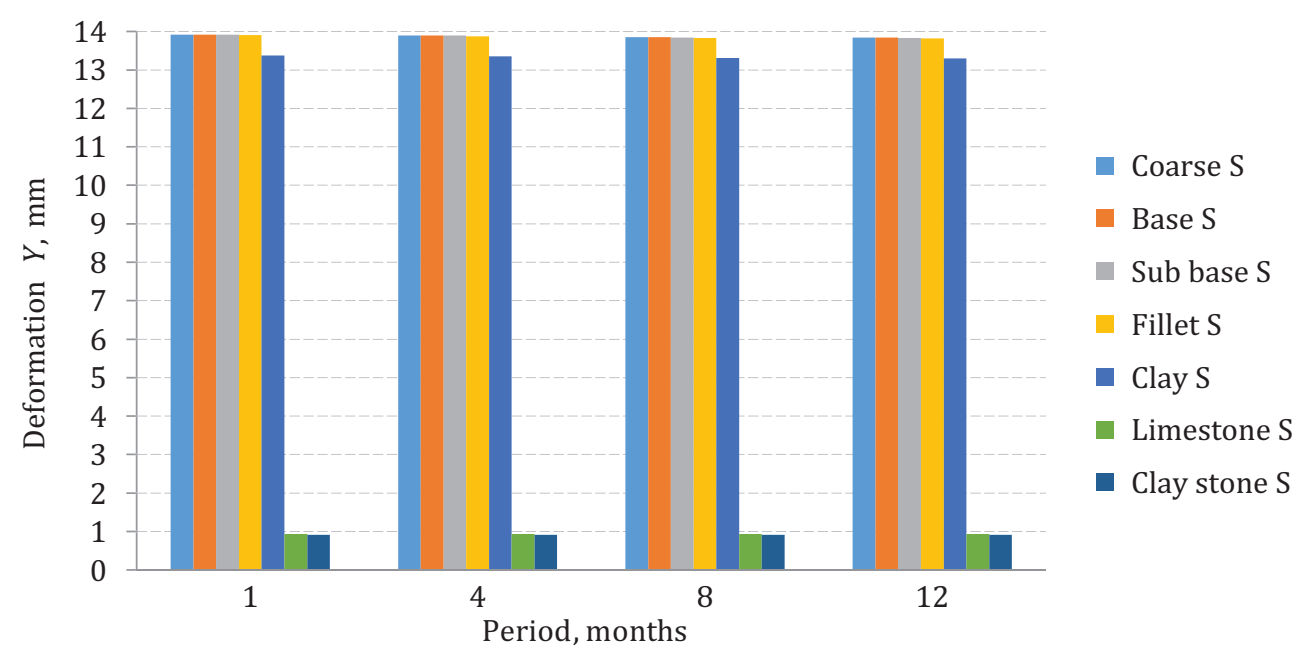

Figure 17. Vertical deformation (y)-time changes of the layers for S type 
and $13.83 \mathrm{~mm}$ in the 12 th month, and in the filler layers $-13.90 \mathrm{~mm}$ in the 1st month and $13.82 \mathrm{~mm}$ in the 12th month. In the SK-Type, in the pavement and base layers, they were determined to be $13.91 \mathrm{~mm}$ in the 1st month, $13.84 \mathrm{~mm}$ in the 12 th month, and in sub-base layers $13.91 \mathrm{~mm}$ in the $1 \mathrm{st}$ month and $13.83 \mathrm{~mm}$ in the 12 th month, and in the filler layers they were $13.89 \mathrm{~mm}$ in the $1 \mathrm{st}$ month and $13.81 \mathrm{~mm}$ in the 12 th month. The deformations in the 5 th clay layers in N-NK-Type between the 1st and 12th months were determined to be $13.38 \mathrm{~mm}$ and $13.31 \mathrm{~mm}$, respectively, and in S-SK-Type - $13.37 \mathrm{~mm}$ and $13.30 \mathrm{~mm}$, respectively. In the 6 th and 7 th limestone and claystone layers, the deformations varied between $0.92 \mathrm{~mm}$ and $0.91 \mathrm{~mm}$, respectively, within one year.

The layer parameters of the road for vertical deformation are presented in Table 12. In Table 12, it was observed that the $R^{2}$ values were close to one for all the layers in terms of vertical deformation within one year, which indicated a strong relationship between the empirical and numerical analyses.

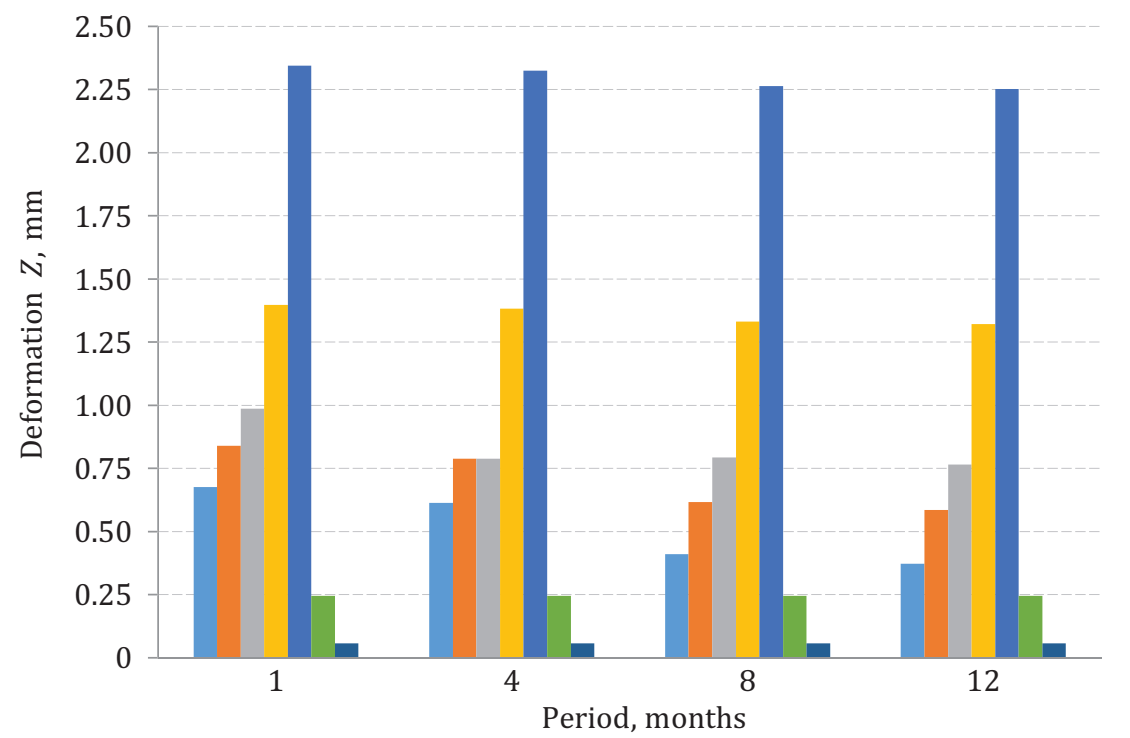

Figure 18. Lateral deformation (z)-time changes of the layers for NK type
Prediction of Mechanical Alteratıons in MultıLayer SBS-Modified Hot Mix Asphalt and Soil-Foundation Structure

- Coarse NK

- Base NK

Sub base NK

- Fillet NK

- Clay NK

- Limestone NK

- Clay stone NK 
Table 12. Function and regression analyses of the relationship between the superstructure and soil layers of the road vertical deformation $(Y)$-Time

\begin{tabular}{|c|c|c|c|}
\hline Layer & Regression models & Mathematical models & $R^{2}$ \\
\hline \multirow{4}{*}{ Coarse } & SK & $y=0.0608 x^{2}-0.3533 x+14.243$ & 0.5000 \\
\hline & S & $y=0.0038 x^{2}-0.0479 x+13.969$ & 0.9558 \\
\hline & NK & $y=0.003 x^{2}-0.0444 x+13.974$ & 0.9284 \\
\hline & $\mathrm{N}$ & $y=0.0005 x^{2}-0.0329 x+13.968$ & 0.8988 \\
\hline \multirow{4}{*}{ Base } & SK & $y=0.0608 x^{2}-0.3533 x+14.243$ & 0.5000 \\
\hline & S & $y=0.0038 x^{2}-0.0479 x+13.969$ & 0.9558 \\
\hline & NK & $y=0.003 x^{2}-0.0444 x+13.974$ & 0.9284 \\
\hline & $N$ & $y=0.0005 x^{2}-0.0329 x+13.968$ & 0.8988 \\
\hline \multirow{4}{*}{ Sub-base } & SK & $y=0.0605 x^{2}-0.3527 x+14.239$ & 0.5014 \\
\hline & S & $y=0.0038 x^{2}-0.0489 x+13.967$ & 0.9585 \\
\hline & NK & $y=0.0028 x^{2}-0.0439 x+13.97$ & 0.9298 \\
\hline & $\mathrm{N}$ & $y=0.0005 x^{2}-0.0333 x+13.964$ & 0.8977 \\
\hline \multirow{4}{*}{ Fillet } & SK & $y=0.0607 x^{2}-0.3547 x+14.225$ & 0.5051 \\
\hline & S & $y=0.0042 x^{2}-0.0518 x+13.954$ & 0.9572 \\
\hline & NK & $y=0.0033 x^{2}-0.0472 x+13.958$ & 0.9271 \\
\hline & $\mathrm{N}$ & $y=0.001 x^{2}-0.0366 x+13.952$ & 0.8955 \\
\hline \multirow{4}{*}{ Clay } & SK & $y=0.0625 x^{2}-0.3595 x+13.702$ & 0.4867 \\
\hline & S & $y=0.0038 x^{2}-0.0449 x+13.419$ & 0.9610 \\
\hline & NK & $y=0.003 x^{2}-0.0414 x+13.423$ & 0.9314 \\
\hline & $\mathrm{N}$ & $y=0.0007 x^{2}-0.0311 x+13.417$ & 0.9040 \\
\hline \multirow{4}{*}{ Limestone } & SK & $y=0.0882 x^{2}-0.4762 x+1.3698$ & 0.3999 \\
\hline & S & $y=-7 E-06 x^{2}+0.0001 x+0.9288$ & 0.9618 \\
\hline & NK & $y=-2 E-06 x^{2}+8 E-05 x+0.9288$ & 0.9428 \\
\hline & $N$ & $y=5 E-06 x^{2}+5 E-05 x+0.9288$ & 0.9191 \\
\hline \multirow{4}{*}{ Claystone } & SK & $y=0.0852 x^{2}-0.4599 x+1.3403$ & 0.3999 \\
\hline & S & $y=-5 \mathrm{E}-06 x^{2}+1 \mathrm{E}-04 x+0.9143$ & 0.9531 \\
\hline & NK & $y=-2 E-06 x^{2}+8 E-05 x+0.9143$ & 0.9167 \\
\hline & $\mathrm{N}$ & $y=2 \mathrm{E}-06 x^{2}+6 \mathrm{E}-05 x+0.9143$ & 0.9051 \\
\hline
\end{tabular}

Polynomial is a function type for the models. 


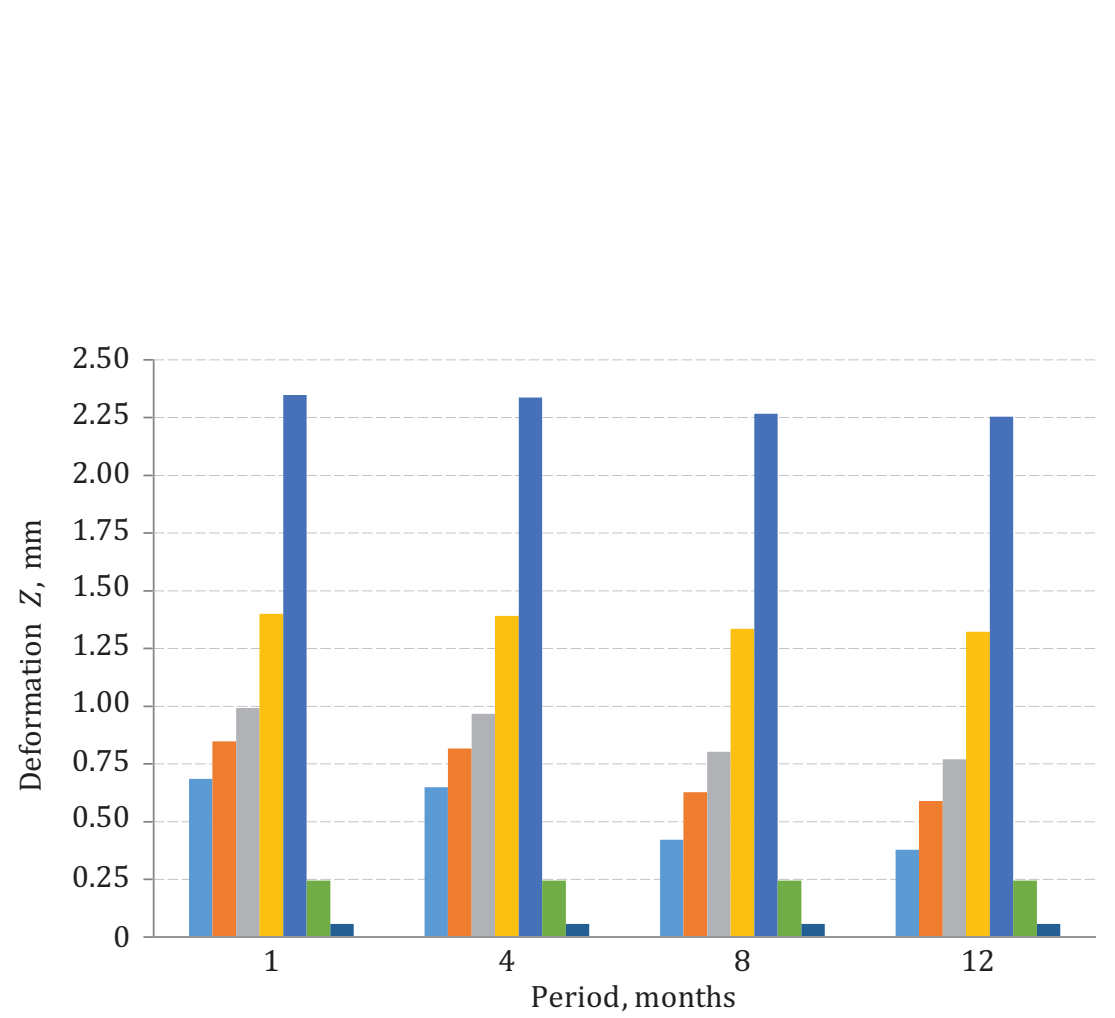

Ahmet Sertac

Karakas,

Faruk Ortes

Prediction

of Mechanical

Alteratıons in Multı-

Layer SBS-Modified

Hot Mix Asphalt

and Soil-Foundation

Structure

- Coarse N

- Base N

- Sub base N

- Fillet N

- Clay N

- Limestone N

- Clay stone $\mathrm{N}$

Figure 19. Lateral deformation ( $z$ )-time changes of the layers for $\mathrm{N}$ type

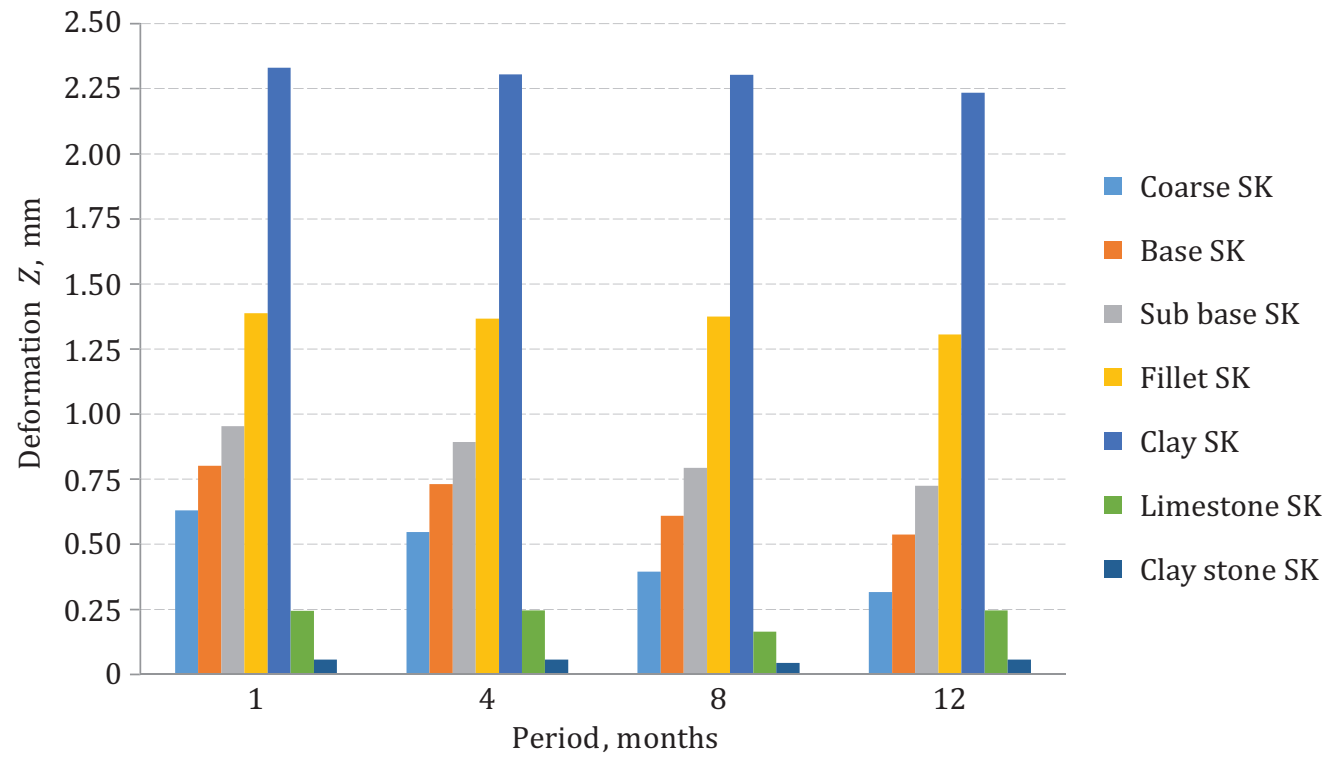

Figure 20. Lateral deformation (z)-time changes of the layers for SK type 
In Figs. 18-21, it was observed that the lateral deformation values increased from the pavement layer towards the lower layers in the 1st month. Furthermore, a decrease was observed in the lateral deformation values in all the layers within one year. The highest lateral deformation was $2.35 \mathrm{~mm}$ in the N-Type 5th clay layer in the 1st month, while the lowest deformation value was $0.0571 \mathrm{~mm}$ for all the pavement layers in the 7 th claystone layers. A decrease of $44.11 \%$ was observed in the lateral deformations in the N-Type pavement layers until the 12th month. The decreases in the lateral deformations in the pavement layers were observed as $44.77 \%$ in the NK-Type, $50 \%$ in the S-Type, and $49.20 \%$ in the SK-Type. Within one year, decreases were also observed in the base layers at a rate of $29.76 \%$ in the lateral deformation values in the N-NKType, $33.73 \%$ in the S-Type, and 32.5\% in SK-Type. In the sub-base layers, decreases were observed in the N-NK-Type at a rate of $22.22 \%$, in the S-Type at a rate of $23.71 \%$, and in SK-Type at a rate of $24.21 \%$. In the 4 th filler layer, decreases were observed in the N-NK-Type at a rate of 5.03\%, and in S-SK at a rate of $5.07 \%$. It was concluded that the deformation values in pure asphalt pavement types were higher than those in the SBS-modified asphalt pavements.

Table 13 presents mathematical models and $R^{2}$ parameters, which were used for different types of layers for horizontal deformation. In Table 13, it was observed that the $R^{2}$ values of the changes in the lateral deformation numerical analysis results within one year were close to one, which indicated a strong relationship among them. For this reason, it was concluded that the numerical analyses were consistent with the empirical studies.

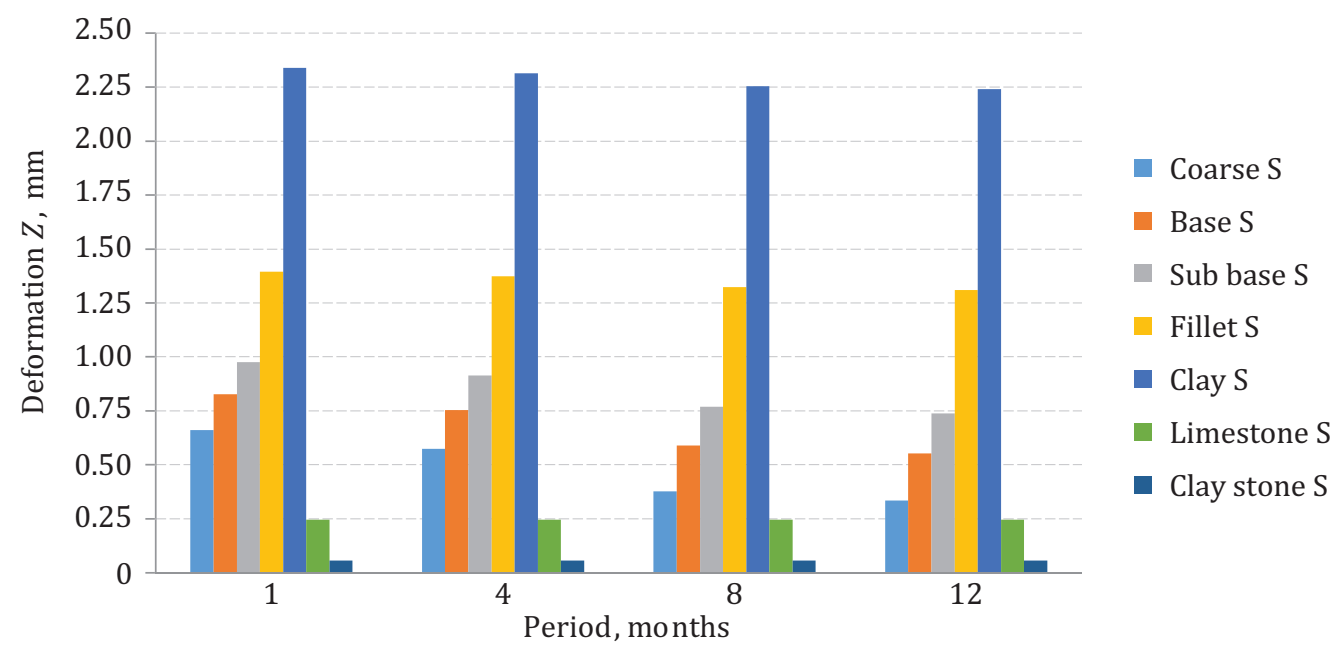

Figure 21. Lateral deformation (z)-time changes of the layers for S type 
Table 13. Function and regression analyses of the relationship between the superstructure and soil layers of the road and lateral deformation ( $Z$ )-Time

\begin{tabular}{|c|c|c|c|c|}
\hline Layer & $\begin{array}{c}\text { Regression } \\
\text { models }\end{array}$ & $\begin{array}{c}\text { Function } \\
\text { type }\end{array}$ & Mathematical models & $R^{2}$ \\
\hline \multirow{4}{*}{ Coarse } & SK & Exponential & $y=0.0016 x^{2}-0.1172 x+0.7532$ & 0.9837 \\
\hline & S & Polynomial & $y=0.0108 x^{2}-0.1714 x+0.8343$ & 0.9535 \\
\hline & NK & Polynomial & $y=0.0062 x^{2}-0.1425 x+0.8274$ & 0.9292 \\
\hline & $\mathrm{N}$ & Exponential & $y=0.897 e^{-0.221} x$ & 0.9068 \\
\hline \multirow{4}{*}{ Base } & SK & Linear & $y=-0.0914 x+0.8988$ & 0.9871 \\
\hline & $\mathrm{S}$ & Polynomial & $y=0.0088 x^{2}-0.1426 x+0.9717$ & 0.9531 \\
\hline & NK & Polynomial & $y=0.005 x^{2}-0.1184 x+0.9658$ & 0.9288 \\
\hline & $\mathrm{N}$ & Exponential & $y=0.9966 e^{-0.135} x$ & 0.9049 \\
\hline \multirow{4}{*}{ Sub-base } & SK & Polynomial & $y=-0.002 x^{2}-0.0689 x+1.0284$ & 0.9920 \\
\hline & $\mathrm{S}$ & Polynomial & $y=0.0074 x^{2}-0.1228 x+1.1003$ & 0.9528 \\
\hline & NK & Polynomial & $y=0.0427 x^{2}-0.279 x+1.2107$ & 0.9109 \\
\hline & $\mathrm{N}$ & Exponential & $y=1.1118 e^{-0.095} x$ & 0.9049 \\
\hline \multirow{4}{*}{ Fillet } & SK & Polynomial & $y=-0.012 x^{2}+0.0367 x+1.3571$ & 0.8561 \\
\hline & $\mathrm{S}$ & Polynomial & $y=0.0022 x^{2}-0.0411 x+1.4365$ & 0.9509 \\
\hline & NK & Polynomial & $y=0.0012 x^{2}-0.0341 x+1.4346$ & 0.9269 \\
\hline & $\mathrm{N}$ & Polynomial & $y=-0.0008 x^{2}-0.0248 x+1.4301$ & 0.9037 \\
\hline \multirow{4}{*}{ Clay } & SK & Polynomial & $y=-0.0108 x^{2}+0.0252 x+2.3114$ & 0.9110 \\
\hline & $\mathrm{S}$ & Polynomial & $y=0.0034 x^{2}-0.0526 x+2.3929$ & 0.9537 \\
\hline & NK & Polynomial & $y=0.0021 x^{2}-0.0445 x+2.3918$ & 0.9292 \\
\hline & $\mathrm{N}$ & Polynomial & $y=-0.0005 x^{2}-0.0327 x+2.3861$ & 0.9028 \\
\hline \multirow{4}{*}{ Limestone } & SK & Polynomial & $y=0.0203 x^{2}-0.1096 x+0.3467$ & 0.3998 \\
\hline & $\mathrm{S}$ & Polynomial & $y=-2 E-06 x^{2}+4 E-05 x+0.2452$ & 0.9618 \\
\hline & NK & Polynomial & $y=-5 E-06 x^{2}+5 E-05 x+0.2452$ & 0.9333 \\
\hline & $\mathrm{N}$ & Linear & $y=2 E-05 x+0.2452$ & 0.9308 \\
\hline \multirow{4}{*}{ Claystone } & SK & Polynomial & $y=0.0031 x^{2}-0.0169 x+0.0728$ & 0.3999 \\
\hline & $\mathrm{S}$ & Polynomial & $y=-5 E-07 x^{2}+5 E-06 x+0.0571$ & 0.9158 \\
\hline & NK & Polynomial & $y=-2 E-07 x^{2}+4 E-06 x+0.0571$ & 0.9618 \\
\hline & $\mathrm{N}$ & Linear & $y=2 E-06 x+0.0571$ & 0.9308 \\
\hline
\end{tabular}

of Mechanical

Alteratıons in MultıLayer SBS-Modified Hot Mıx Asphalt and Soil-Foundation Structure 


\section{Conclusions}

To reveal the performance of roads in a detailed manner and to determine their mechanical responses under traffic and environmental conditions, empirical studies that are conducted under laboratory and field conditions can be performed. Especially, due to the limited number of raw materials, it is necessary to use an additive to improve the performance characteristics of asphalt concrete pavements and to make them serve for longer periods. In this study, SBS-modified bitumen was chosen as the polymer material in HMA to improve the service quality throughout the service life of the superstructure of the roads. Accordingly, the obtained stress and deformation values of SBS modified HMA from the numerical simulations were compared with those obtained representing unmodified HMA. Furthermore, the mechanical changes in asphalt concrete pavements within one year under traffic and environmental conditions were examined within the framework of the study. Stress and deformations were evaluated for both superstructure of the road and natural ground layer so that the results allowed us to perceive the mechanical interactions between neighbouring layers and the entire body of asphalt pavement. The Von Mises stresses and deformations occurring in both lateral and vertical directions in the superstructure of the road and natural ground layers were compared with ones for SBS modified and unmodified asphalt pavement by using empirical and numerical analyses. As a result, it was determined that using SBS-polymer additives improved the endurance of the roads in terms of deformations, which resulted from the weight of the roads and the traffic volume throughout the service life of the pavements. It was also determined that the environmental conditions, such as the climate and the traffic volume, affected the endurance of the roads. Especially, the environmental conditions, such as the climate, led to oxidation in the bitumen, which was included in the structure of the HMA, in time and caused deformation by influencing the properties of binders. Furthermore, the evaporation in hot weather, the extreme rigidity in the pavement in cold weather, wheel tracks, and the constant change in temperatures caused cracks in pavements. It was discovered that the use of SBS-modification improved the endurance against fatigue, which was caused by repetitive traffic load in asphalt pavements. Since roads transfer the vehicle loads on them to the lower layers, the preference of material in the lower layers and the pressure levels must be made according to the standards. To ensure that the rainwater does not damage the roads, the crosswise and lengthwise inclinations of the roads must be proper, and a drainage system should be established to drain the water when necessary. In laboratory and field tests, it was 
discovered that using SBS-modification in bitumen in HMA significantly contributed to the prevention of deformations due to stress parameters and the reduction of degradations in mechanical properties.

\section{Suggestions for future studies}

- The experiments can be conducted with different pressure parameters.

- Studies may be conducted under different climate conditions where continental climatic conditions are dominant.

- Empirical studies can be conducted in areas where heavy vehicle volume is intense.

- Performance properties can be compared under traffic and environmental conditions within certain periods by investigating them on types of superstructures with different types of polymers.

- Field performance tests can be performed by considering longer periods while determining the mechanical properties of asphalt pavements.

- High-temperature behaviours, as well as low-temperature behaviours, can be tested in laboratories for asphalt pavements.

- Stress tests can be performed as performance tests for asphalt pavements.

- Finite element studies that are conducted by applying dynamic analyses can be designed in numerical analyses.

- Studies can be conducted by adopting the numerical analysis method and considering the non-linear properties of the materials.

\section{Acknowledgements}

The authors would like to thank Istanbul Transportation Line and Fixed Facilities Directorate for material supply. The authors are also grateful to BIMTAS, ISFALT companies and professors of the Transportation Department of Firat University for giving the opportunity to conduct laboratory tests.
Prediction of Mechanical Alteratıons in MultıLayer SBS-Modified Hot Mix Asphalt and Soil-Foundation Structure 


\section{Funding}

The research was supported by the FUBAP\#1 under Grant [1970]; TUBITAK\#2 under Grant [2219].

\section{REFERENCES}

Ahmedzade P., Kuloglu N., Ahmedzade M., Karakas A. S., Kuloglu M., \& Yilmaz M. (2007). Examination of the Rheological Properties of Pure and SBS Modified Bitumen Classical and Superpave Method. Firat University Scientific Research Projects Unit, Project No. 2003K120440.

Akbulut, H., \& Aslantas, K. (2005). Finite element analysis of stress distribution on bituminous pavement and failure mechanism. Materials \& Design, 26(4), 383-387. https://doi.org/10.1016/j.matdes.2004.05.017

Ameri, M., Mansourian, M., Khavas, H., Aliha, M. R. M., \& Ayatollahi, M. R. (2011). Cracked asphalt pavement under traffic loading - A 3D finite element analysis, Engineering Fracture Mechanics, 78(8), 1817-1826.

https://doi.org/10.1016/j.engfracmech.2010.12.013

Boussinesq, J. (1885). Application des Potentials an L'etude de L'equilbre et du Movement des Solids Elastiques. Gauthier-Villars, Paris.

Burland, J. B., Broms, B. B., \& De Mello, V. F. B. (1977). Behavior of foundations and structures, In Proceedings of the 9th international conference on soil mechanics and Foundation Engineering, Tokyo, pp. 495-538.

Chen, J. S., \& Huang, C. C. (2007). Fundamental characterization of SBS-modified asphalt mixed with sulfur. Journal of Applied Polymer Science, 103(5), 2817-2825. https://doi.org/10.1002/app.24621

Deng, W., Zhang, X., Chen, B., \& Yan, S. (2004). Nonlinear FEM analysis of the influence of asphalt pavement under a non-homogenous settlement of roadbed. China Journal of Highway and Transport, 1, 16-19.

Hinislioglu, S., Agar, E. (2004). Use of waste high-density polyethylene as bitumen modifier in asphalt concrete mix. Materials Letters, 58(3-4), 267-271. https://doi.org/10.1016/S0167-577X(03)00458-0

Karakas, A. S. \& Ortes, F. (2017). Comparative assessment of the mechanical properties of asphalt layers under the traffic and environmental conditions. Construction and Building Materials, 131, 278-290. https://doi.org/10.1016/j.conbuildmat.2016.11.049

Karakaş, A. S., Sayin, B., \& Kuloglu, N. (2014). The changes in the mechanical properties of neat and SBS-modified HMA pavements due to traffic loads and environmental effects over a one-year period. Construction and Building Materials, 71, 406-415. https://doi.org/10.1016/j.conbuildmat.2014.08.060

Karakas, A. S., Kuloglu, N., Kok, B. V., \& Yilmaz, M. (2015). The evaluation of the field performance of the neat and SBS modified hot mixture asphalt. Construction and Building Materials, 98, 678-684. https://doi.org/10.1016/j.conbuildmat.2015.08.140 
Keskin, M. S., Laman, M., \& Baran, T. (2008). Experimental determination and numerical analysis of vertical stresses under square footings resting on sand. Digest, 2008, 1263-1279.

Kim, H., Wagoner, M. P., \& Buttlar, W. G. (2009). Numerical fracture analysis on the specimen size dependency of asphalt concrete using a cohesive softening model. Construction and Building Materials, 23(5), 2112-2120. https://doi.org/10.1016/j.conbuildmat.2008.08.014

Li, X. J., \& Marasteanu, M. O. (2010). The fracture process zone in asphalt mixture at low temperature. Engineering Fracture Mechanics, 77(7), 1175-1190. https://doi.org/10.1016/j.engfracmech.2010.02.018

Li, Q., Yang, H., Ma, X., \& Ni, F. (1935). Evaluation of microstructure and damage evolution for asphalt pavements in an advanced repeated load permanent deformation test using X-ray computed tomography. Road Materials and Pavement Design, 2016, 1-24.

McLean, Va. (2010). Long-Term Pavement Performance Program Highlights: Accomplishments and Benefits 1989-2009. FHWA-HRT-10-071. Federal Highway Administration, Turner-Fairbank Highway Research Center.

Newmark, N. M. (1935). Simplified computation of vertical pressures in elastic foundations, University of Illinois Engineering. Experiment Station, Circular No. 24, Illinois.

Novak, M., Birgisson, B., \& Roque R. (2003). Near-surface stress states in flexible pavements using measured radial tire contact stresses and ADINA. Computers \& Structures, 81(8-11), 859-870. https://doi.org/10.1016/S0045-7949(02)00413-3

Norouzi, A., Kim, D., \& Kim, Y. R. (2016). Numerical evaluation of pavement design parameters for the fatigue cracking and rutting performance of asphalt pavements. Materials and Structures, 49(9), 3619-3634. https://doi.org/10.1617/s11527-015-0744-x

Prowell, B., Hurley, G., \& Crews, E. (2007). Field Performance of Warm-Mix Asphalt at National Center for Asphalt Technology Test Track. Transportation Research Record: Journal of the Transportation Research Board, 1998, 96-102. https://doi.org/10.3141/1998-12

Sengoz B., \& Isikyar, G. (2008). Evaluation of the properties and microstructure of SBS and EVA polymer modified bitumen. Construction and Building Materials, 22(9), 1897-1905. https://doi.org/10.1016/j.conbuildmat.2007.07.013

Sheng, L., Huang, Y., \& Liu, Z. (2016). Experimental evaluation of asphalt material for interlayer in rigid-flexible composite pavement. Construction and Building Materials, 102, 699-705. https://doi.org/10.1016/j.conbuildmat.2015.10.122

Siddharthan, R., Yao, J., \& Sebaaly, P. E. (1998). Pavement strain from moving dynamic 3D load distribution. Journal of Transportation Engineering, 124(6), 557-566. https://doi.org/10.1061/(ASCE)0733-947X(1998)124:6(557)

Tarefder, R. A., \& Zaman, A. (2016). Carbon nanotube modified asphalt binders for sustainable roadways. In Stanton N., Landry S., Di Bucchianico G., Vallicelli A. (eds) Advances in Human Aspects of Transportation. Advances in
Ahmet Sertac

Karakas,

Faruk Ortes

Prediction

of Mechanica

Alteratıons in Multı-

Layer SBS-Modified

Hot Mix Asphalt

and Soil-Foundation

Structure 
Intelligent Systems and Computing, vol. 484. Springer, Cham. (pp. 623-633). https://doi.org/10.1007/978-3-319-41682-3_52

Ullidtz, P. (1987). Pavement Analysis. Developments in Civil Engineering, 19, 318.

Westergaard, H. M. (1938). A Problem of elasticity suggested by a problem in soil mechanics: soft material reinforced by numerous strong horizontal sheets. In Contributions to the mechanics of solids, S. Timoshenko 60th Anniversary Volume, New York - Mac Millan.

Wu, S., Xue, Y., Ye, Q., \& Chen, Y. (2007). Utilization of steel slag as aggregates for stone mastic asphalt (SMA) mixtures. Building and Environment, 42(7), 2580-2585. https://doi.org/10.1016/j.buildenv.2006.06.008

Xiao, F., Amirkhanian, SN., Shen, J., \& Putman, B. (2009). Influences of crumb rubber size and type on reclaimed asphalt pavement (RAP) mixtures. Construction and Building Materials, 23(2), 1028-1034. https://doi.org/10.1016/j.conbuildmat.2008.05.002

Yang, Y., Sun, H., Zhan, G., \& Liu, F. (2015). The Analysis on the Influence of Porosity on the Pavement Performance of Asphalt Mixture under Heavy Traffic. Journal of Liaoning Provincial College of Communications, 4, 002.

Yao, H., \& You, Z. (2016). Nanoclay modified asphalt. In Innovative Developments of Advanced Multifunctional Nanocomposites in Civil and Structure Engineering (pp. 183-216). https://doi.org/10.1016/B978-1-78242-326-3.00009-9

Zafir, Z., Siddharthan, R., \& Sebaaly, P. (1994). Dynamic pavement-strain histories from moving traffic load. Journal of Transportation Engineering, 120(5), 821-842. https://doi.org/10.1061/(ASCE)0733-947X(1994)120:5(821)

Zeng, F., \& Huang, X. (2004). Asphalt pavement stress under overloading. Journal of Traffic and Transportation Engineering, 3, 003. 